\title{
Multi-Scale Modeling of Texture Evolution in Beryllium and Zirconium during Equal Channel Angular Extrusion
}

\author{
I. J. Beyerlein ${ }^{1, a}$, L. Capolungo ${ }^{1, b}$, G. G. Yapici ${ }^{2, c}$, C. N. Tomé ${ }^{1, d}$ \\ and I. Karaman ${ }^{3, \mathrm{e}}$ \\ ${ }^{1}$ Los Alamos National Laboratory, Los Alamos, NM 87545, USA \\ ${ }^{2}$ Schlumberger Technology Corporation, Rosharon, TX 77583, USA \\ ${ }^{3}$ Texas A\&M University, College Station, TX 77843, USA \\ airene@lanl.gov, 'laurentc@lanl.gov, 'gyapici@slb.com, 'tome@lanl.gov, ${ }^{\mathrm{a} i k a r a m a n @ t a m u . e d u ~}$
}

Keywords: Texture, ECAP, beryllium, zirconium, large strains, strain path changes, dislocations.

\begin{abstract}
This work studies the deformation mechanisms active in two pure hexagonal close packed metals, beryllium $(\mathrm{Be})$ and zirconium $(\mathrm{Zr})$, during equal channel angular extrusion processing. An experimental-theoretical approach is employed to assess their relative contributions through measurement and calculation of texture evolution. A new multi-scale constitutive model, incorporating thermally activated dislocation density based hardening, is shown to effectively predict texture evolution as a function of processing route, number of passes (up to four), initial texture, pressing rate, and processing temperature. Texture predictions are shown to be in very good agreement with experimental measurements. Also, it is found that the two most active deformation modes in Be are basal slip and prismatic slip, where the predominant one is interestingly found to depend on die angle. Deformation in $\mathrm{Zr}$ during the first pass is predicted to be accommodated not only by its easiest mode, prismatic slip, but by basal slip and tensile twinning.
\end{abstract}

\section{Introduction}

There is a growing interest in fabricating ultra-fine grained metals with a hexagonal close packed (hcp) crystal structure via severe plastic deformation (SPD) techniques in order to improve their mechanical properties (e.g yield strength). One such technique, equal channel angular extrusion (ECAE) [1], also referred to as equal channel angular pressing (ECAP), has been applied to Ti [25], $\mathrm{Mg}$ [6-12], Be [13-15], and $\mathrm{Zr}$ [16-21]. As compared to cubic metals, hep metals are not as widely studied or as well understood. Hcp metals deform by simultaneous activation of several slip and twinning modes, which makes them more interesting, but also much more complex, to understand than face center cubic $\mathrm{Cu}, \mathrm{Al}$, or Ni. Many elementary processes, such as twin nucleation [22] and interactions between slip dislocations of different types, are not well understood.

In this work we study texture evolution in pure Be and $\mathrm{Zr}$ during ECAE using a multi-scale constitutive model. These two hcp metals and their alloys are used in nuclear applications, where knowledge of their structural performance is needed. Material texture is one of the important microstructural features for understanding and predicting their deformation behavior [23,24]. Texture evolution depends on the number and type of slip and twin modes active in each crystal. Two different sets of activated systems in a crystal will result in different stress states, shear strains, and hence, lattice reorientations. In an hcp crystal, there is more than one slip mode available to accommodate deformation along the $<\mathrm{a}>$ axis and, several slip and twinning modes for deformation along the $\langle\mathrm{c}>$ axis. The ones that are observed depend most of all on the type of hcp metal. In the case of Be, the easiest slip mode is $<\mathrm{a}>$ basal slip and the preferred $<\mathrm{c}+\mathrm{a}>$ slip mode is $2^{\text {nd }}$ order pyramidal $<\mathrm{c}+\mathrm{a}>\operatorname{slip}$, whereas for $\mathrm{Zr}$, it is $<\mathrm{a}>$ prismatic slip and $1^{\text {st }}$ order pyramidal $<\mathrm{c}+\mathrm{a}>\operatorname{slip}$, respectively. For a given material, the relative contribution of each has been shown to depend on crystal orientation, temperature, and strain rate. 
The overarching goal of our program is to develop a multi-scale model for SPD metal processing. While multi-scale understanding of the SPD process may not be necessary for texture predictions alone, it is critical in future development of a computational tool that can predict coupled texture evolution, microstuctural evolution, and mechanical behavior. The multiscale constitutive model used here and the corresponding material parameters for $\mathrm{Be}$ and $\mathrm{Zr}$ have been presented in previous work [21,23-25]. The model, however, was validated with mechanical tests involving temperatures, strain rates, strain levels, and/or boundary conditions significantly different than those imposed by ECAE. As a first step for SPD applications, the predictive capability of the same model is tested against texture measurements made on $\mathrm{Be}$ and $\mathrm{Zr}$ processed by ECAE from one to four passes. The model also provides insight on the deformation mechanisms activated during each pressing schedule which differed in temperature, strain rate, and route.

\section{Materials and ECAE processing}

The three starting hep metals investigated in this work are listed in Table 1. The first material is powder metallurgy source $\mathrm{Be}(0.72 \mathrm{wt} \% \mathrm{BeO})$, designated as $\mathrm{P} 31664$, produced by the BrushWellman Company by vacuum hot pressing of attrited powder. The second material is a commercial powder metallurgy source Be, designated as s200F. Both Be samples had a weak initial texture (see Fig. 1a). The last material is acquired as high-purity crystal bar $\mathrm{Zr}$ with sufficiently low interstitial impurities $(<100 \mathrm{ppm})$. The crystal bar is vacuum arc-melted and cast into an ingot. The ingot is then processed by knockdown forging followed by several passes through a rolling mill at room temperature [26]. The final product is a clock-rolled plate with a strong axisymmetric texture. The basal pole figure of $\mathrm{Zr}$ is represented in Figs. $1 \mathrm{~b}$ and $1 \mathrm{c}$ in the two initial sample orientations tested. Annealing at $550^{\circ} \mathrm{C}$ for one hour left the grains free of twins and equiaxed with an average diameter of $\sim 15-25 \mu \mathrm{m}$. Before ECAE processing, square-section billets of each material were placed in a metal jacket made of commercial purity $\mathrm{Ni}$. For Be, the jacket was a relatively thin protective layer, whereas for $\mathrm{Zr}$, the jacket was $8.7 \mathrm{~mm}$ in thickness.

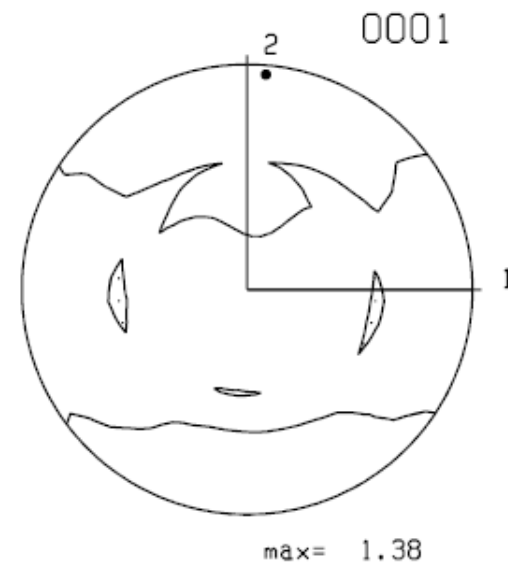

(a)

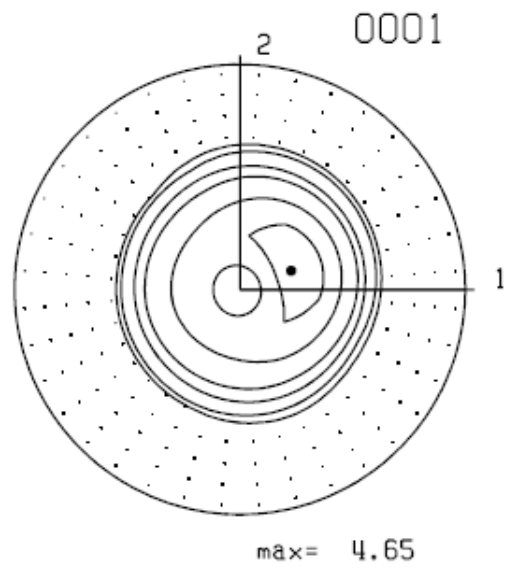

(b)

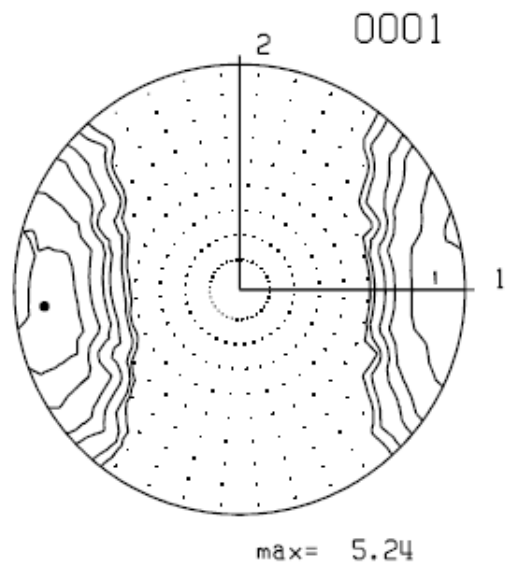

(c)

Figure 1. Basal pole figures of measured initial textures of the (a) pure $\mathrm{Be}$; (b) and (c) pure $\mathrm{Zr}$ in the two initial configurations tested. All sample textures are shown with respect to the ECAE die axes with the 2-axis aligned with a vertical entry channel and the 3 -axis lying perpendicular to the plane of the die. Contour levels: 0.8/1.0/1.5/2.0/3.0/4.0 $\mathrm{mrd}$

The jacketed samples were ECAE-processed under different conditions. For the first Be material, the ECAE tooling had a sharp outer corner, channel width $w=25.4 \mathrm{~mm}$, and a $90^{\circ}$ die 
angle. Pressing was carried out at $425^{\circ} \mathrm{C}$ at a pressing rate of $25.4 \mathrm{~mm} / \mathrm{s}$. Texture measurements were taken after the first pass and tje second pass of route $\mathrm{A}$ and route $\mathrm{C}$ by X-ray diffraction [14]. The other Be starting material was processed at the same temperature but at a lower pressing rate, 2.54-6.35 mm/s. Several samples were processed via route Bc using a sharp corner die with die angle $90^{\circ}$ or $120^{\circ}$ and smaller $w=9.5 \mathrm{~mm}$. Texture measurements were taken after $1,2,3$, and 4 passes with $120^{\circ}$ and only after 4 passes with $90^{\circ}$ by the time-of-flight HIPPO (High-Pressure Preferred Orientation) neutron diffractometer at Los Alamos Neutron Science Center LANSCE [15]. Finally, the pure $\mathrm{Zr}$ sample was processed using an ECAE die with a sharp outer corner, $w=$ $25.4 \mathrm{~mm}$, and $90^{\circ}$ die angle at room temperature and at a pressing rate of $0.03 \mathrm{~mm} / \mathrm{s}[21]$. Texture measurements after one pass were also obtained by HIPPO at LANSCE. This information and references, where processing details can be found, are summarized in Table 1.

Table 1. Summary of the materials studied here and their ECAE processing conditions

\begin{tabular}{|l|l|l|l|l|l|l|l|l|}
\hline Material & $\begin{array}{l}\text { Initial } \\
\text { Texture }\end{array}$ & $\begin{array}{l}\text { Grain } \\
\text { size } \\
(\mu \mathrm{m})\end{array}$ & $\begin{array}{l}\text { Die } \\
\text { angle }\end{array}$ & $\begin{array}{l}\text { Pressing } \\
\text { rate } \\
(\mathrm{mm} / \mathrm{s})\end{array}$ & $\begin{array}{l}\text { Temp } \\
(\mathrm{K})\end{array}$ & $\begin{array}{l}\text { Channel } \\
\text { die } \\
\text { width } \\
(\mathrm{mm})\end{array}$ & $\begin{array}{l}\text { Passes } \\
\text { and } \\
\text { Routes }\end{array}$ & Ref. \\
\hline Pure Be & weak & 25 & $90^{\circ}$ & 25.4 & 698 & 25.4 & $\begin{array}{l}1,2 \mathrm{~A}, \\
2 \mathrm{C}\end{array}$ & {$[14]$} \\
\hline Pure Be & weak & 25 & $120^{\circ}$ & $\begin{array}{l}2.54- \\
6.35\end{array}$ & 698 & 9.5 & $\begin{array}{l}1,2 \mathrm{Bc}- \\
4 \mathrm{Bc}\end{array}$ & {$[15]$} \\
\hline Pure Be & weak & 25 & $90^{\circ}$ & $\begin{array}{l}2.54- \\
6.35\end{array}$ & 698 & 9.5 & $4 \mathrm{Bc}$ & {$[15]$} \\
\hline Pure $\mathrm{Zr}$ & strong & $15-25$ & $90^{\circ}$ & 0.03 & 298 & 25.4 & 1 & {$[21]$} \\
\hline
\end{tabular}

\section{Polycrystal model for texture evolution}

In the present study, the hcp metal is modeled as a plastic polycrystal and elastic deformation is neglected. This assumption is reasonable for modeling ECAE, where the plastic contribution to deformation is much larger than the elastic one.

Dislocation slip and twinning systems operate on specific crystallographic planes and directions. The kinematics of each slip system can be defined by its glide plane, where $n^{\text {s }}$ denotes the unit vector normal to the glide plane, and its slip direction, where $b^{s}$ denotes the unit vector parallel to the glide direction. Several slip modes $\alpha$ and twin modes $\beta$ can be activated. A mode ,or family, contains systems whose glide planes and directions share the same crystallography. Basal slip $(\alpha=$ 1 , no. of systems $=3)$ and prismatic slip $(\alpha=2$, no. of systems $=3)$ are examples of two different slip families.

Plastic deformation of each crystal is defined by a plastic velocity gradient $L^{\mathrm{c}}$. $L^{\mathrm{c}}$ is defined as the sum of the shear rates $\dot{\gamma}^{s}$ on the individual slip and twinning systems $s$ :

$$
L^{c}=\sum_{s}\left(n^{s} \otimes b^{s}\right) \dot{\gamma}^{s}
$$

$L^{\mathrm{c}}$ can be decomposed further into its symmetric $D^{\mathrm{c}}$ and skew $W^{\mathfrak{c}}$ parts. In the above, $\otimes$ denotes a tensor product.

$$
L^{\mathrm{c}}=D^{\mathrm{c}}+W^{\mathrm{c}}
$$


Shear deformation is associated with the plastic strain rate $D^{\mathrm{c}}$ and lattice reorientation is related to the plastic spin $W^{c}$. $W^{\mathfrak{c}}$ is used to update the crystal orientation and hence calculate texture evolution $[27,28]$.

Several models for the shear rate $\dot{\gamma}^{s}$ in system $s$ can be employed. Here, a visco-plastic power law [29], relating $\dot{\gamma}^{s}$ to the total Cauchy stress $\sigma^{\mathfrak{c}}$ to the power $n$, is used:

$$
\dot{\gamma}^{s}=\dot{\gamma}_{0}\left|\frac{m^{s}: \sigma^{c}}{\tau_{c}^{s}}\right|^{n} \operatorname{sign}\left(m^{s}: \sigma^{c}\right)=\dot{\gamma}_{0}\left|\frac{\tau_{r s s}^{s}}{\tau_{c}^{s}}\right|^{n} \operatorname{sign}\left(\tau_{r s s}^{s}\right)
$$

and

$$
m^{s}=\frac{1}{2}\left(n^{s} \otimes b^{s}+b^{s} \otimes n^{s}\right)
$$

where $\tau_{c}^{s}$ is the critical resolved shear stress for system $s$, and : denotes a contracted tensor product. In Eq. 3, the relevant stress measure to activate the system is the resolved shear stress $\tau_{r s s}^{s}$, defined as:

$$
\tau_{r s s}^{s}=m^{s}: \sigma^{c}=m^{s}: S^{c}-p(b \cdot n)=m^{s}: S^{c}
$$

where $S^{c}$ is the deviatoric stress component of $\sigma^{\mathcal{E}}$. Eqs. 3 and 5 emphasize that $\dot{\gamma}^{s}$ and $\tau_{r s s}^{s}$ depend only on the deviatoric stress component $S^{c}=\sigma^{\mathcal{E}}-p \mathrm{I}$, and not on the hydrostatic pressure $p$. According to Eq. 3, any system with a non-zero $\tau_{r s s}^{s}$ will be active and the higher $\tau_{r s s}^{s}$, the higher $\dot{\gamma}^{s}$. We set $n=20$, which means that $\tau_{r s s}^{s}$ must be close to $\tau_{c}^{s}$ in order for the system to contribute significantly to deformation.

Eq. 3 was originally developed for slip and not twinning. In the present model, it is applied to twinning systems as well. It has been argued, however, that twin growth kinetics may be governed by mechanisms other than a critical value of $\tau_{r s s}^{s}$, implied by Eq. 3. Application of Eq. 3 for twinning in single crystal $\mathrm{Mg}$ was recently compared with an alternative rate law motivated by MD simulations in [30] and there it was concluded that it least for twin growth (not twin nucleation) Eq. 3 was more appropriate than the alternative.

From the above, the single crystal constitutive law relating stress to strain-rate can be written explicitly as:

$$
D^{c}=\sum_{s} m^{s} \dot{\gamma}_{0}\left|\frac{m^{s}: \sigma^{c}}{\tau_{c}^{s}}\right|^{n} \operatorname{sign}\left(m^{s}: \sigma^{c}\right)
$$

A polycrystal model is then used to relate the macroscale velocity gradient $L$ to the local plastic velocity gradient in each grain $L^{\mathrm{c}}$. The polycrystal model used in this work is the visco-plastic selfconsistent scheme (VPSC) [27,28]. VPSC uses localization and globalization equations to calculate $D^{\mathrm{c}}, W^{\mathrm{c}}$, and $\sigma^{\mathrm{c}}$ for each grain and, an effective viscoplastic compliance for the polycrystal at each time step (or strain increment). Each grain is treated as a visco-plastic ellipsoidal inclusion embedded in a visco-plastic homogeneous effective medium (HEM) solution of the macroscopic problem. With this assumption, a linearized form of the relationship between $D^{\mathrm{c}}$ and $\sigma^{\mathfrak{c}}$ (Eq. 6), and 
the macrohomogeneity condition, the local-global relationships can be found via solution of an elementary inclusion problem similar to that of Eshelby [31]. This approach results in uniform $L^{\mathrm{c}}$ and $\sigma^{\varepsilon}$ within each grain. $D^{\mathrm{c}}, W^{\mathrm{c}}$, and $\sigma^{\mathfrak{c}}$ for each crystal is then related to the macroscopic values $D, W$, and $\sigma$ via a set of coupled interaction equations [27,28]. The weighted average of $D^{\mathrm{c}}$ and $W^{\mathrm{c}}$ over all crystals in the aggregate must equal the applied $D$ and $W$. Note here, that, due to the pronounced plastic anisotropy of hcp metals, the use of a self-consistent approach is better suited than that of a Taylor type model, where all crystals are assumed to be in the same state of strain as the macroscopic one, or of a Sachs model in which all grains are in the same state of stress at the macroscopic one.

Components of the model that require further description are (1) expressions for the average polycrystal velocity gradient $L$ associated with ECAE deformation, (2) extensions made to VPSC for large strain deformation, and (3) hardening laws that describe the evolution of $\tau_{c}^{s}$ for both, slip and twinning ( $s$ belongs to $\alpha$ or $\beta$ respectively). These three will be described next.

\section{Fan model description of ECAE deformation}

In each pressing, the billet undergoes intense shearing as it travels around the ECAE die corner. An idealized view of this deformation is simple shearing concentrated along the intersection plane of the two channels. Ideal simple shearing applies best when the material is rigid plastic, the inner and outer corners are sharp, and the die-billet interface is frictionless [32]. It is often the case that the material is strain hardening or the outer corner is rounded. In this event, deformation takes place over a broad plastic deformation zone (PDZ) roughly in the shape of a fan [33,34].

The velocity gradients associated with both simple shearing and the development of a PDZ are defined using the fan model developed in [2,35]. It was first developed for a $\Phi=90^{\circ}$ die and later extended to any die angle $\Phi$. For the present work, the PDZ assumes the shape of an ideal fan. The fan is considered to be 'ideal' when it extends from the inner to the outer corner, it is symmetric, and the fan angle, $\beta_{\mathrm{m}}$, is constant. The $\mathrm{PDZ}$ is then completely described by $\beta_{\mathrm{m}}$. Figure 2 illustrates an ideal fan with angle $\beta_{\mathrm{m}}$ along with the other material parameters. OW and OW' are the throughthickness directions, normal to the channel entry axis and exit axis respectively. The fan-shaped zone is equidistant by an angle $\alpha$ from both OW and OW'. The inner angle of the fan, $\beta_{\mathrm{m}}$, is

$$
\beta_{\mathrm{m}}=\pi-\Phi-2 \alpha
$$

which ranges from 0 to $\pi-\Phi$ as $\alpha$ decreases from $(\pi-\Phi) / 2$ to 0 . The maximum value of $\beta_{\mathrm{m}}$ is:

$$
\beta_{\max }=\pi-\Phi
$$

The location of the inner corner of the die is assigned $\left(O_{\mathrm{x}}, O_{\mathrm{y}}\right)=(w, w)$. Any given flow line begins at $t=0$ and at $X_{0}=\left(x_{0}, y_{0}, \mathrm{z}_{0}\right)$ inside the die, i.e. $0<x_{0}<w, 0<y_{0}<w$. Deformation is assumed uniform in $z$. Note that generally when $\beta_{\mathrm{m}}>0^{\circ}$, the outermost flow line, starting at $x_{0}=0$, does not fill the outer corner.

Consider the flow of a material point which originates at $X_{0}=\left(x_{0}, y_{0}, \mathrm{z}_{0}\right)$ in the billet at $t=0$. It flows down the entry channel at the pressing velocity $V$ until $t=t_{1}$, where it experiences shearing at the first boundary. For $t>t_{1}$, it takes a circular path until $t=t_{2}$, where it encounters the second boundary. Between $t_{1} \leq t \leq t_{2}$, the angular location $\beta(t)$ of the material point from the first boundary (See Fig. 2) changes according to

$$
\beta(t)=\frac{V\left(t-t_{1}\right) \cos ^{2} \alpha}{\left(w-x_{0}\right)}=\frac{\left(t-t_{1}\right)}{t_{n}} \cos ^{2} \alpha \quad t_{1} \leq t \leq t_{2}
$$




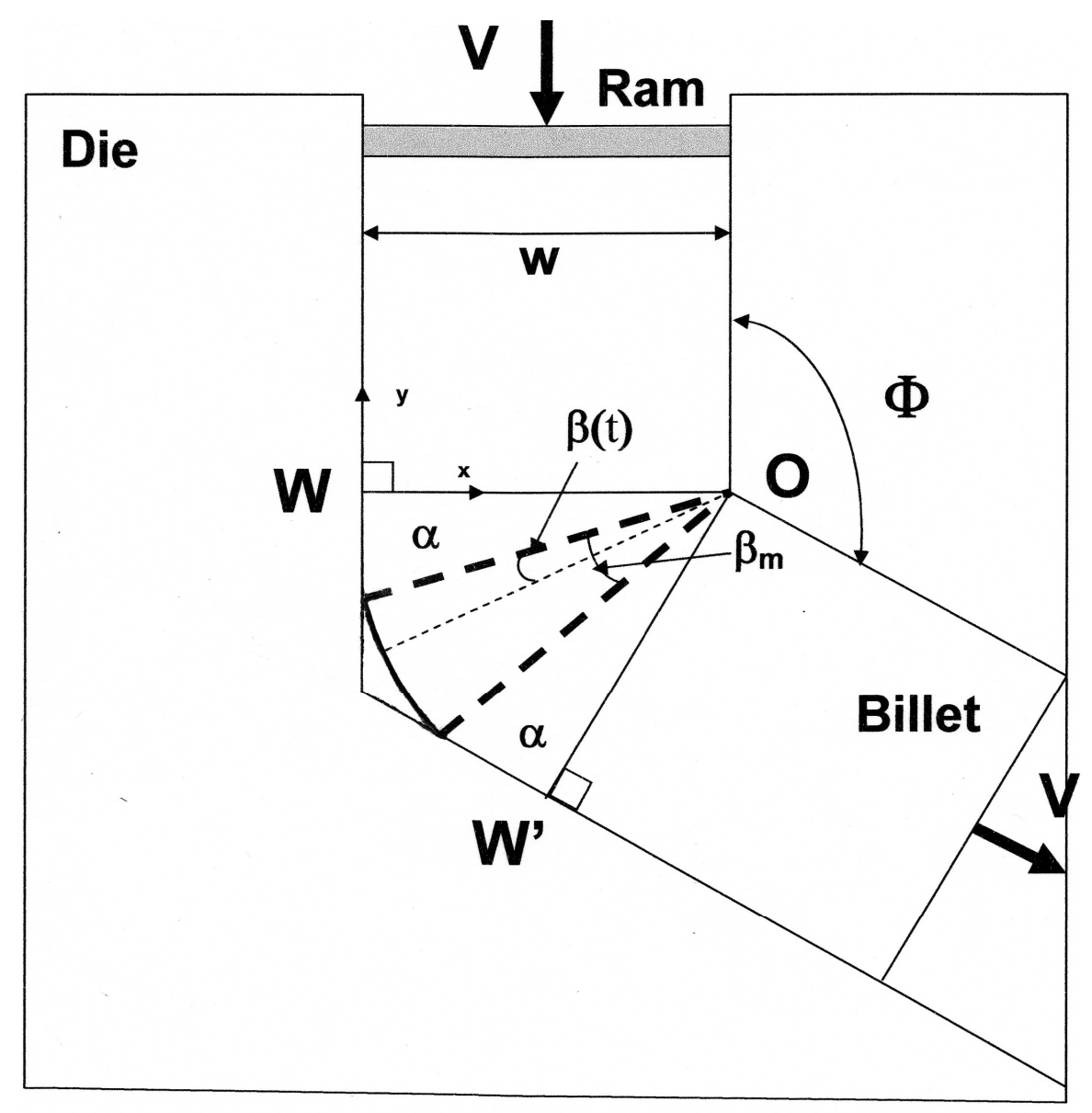

Figure 2. Illustration of the ideal fan model of a broad plastic deformation zone developing at the die-channel intersection region of the ECAE die with arbitrary die angle $\Phi$. The $x-y$-z coordinate system shown corresponds to the 1-2-3 axes in Fig. 1.

where the timescale $t_{\mathrm{n}}=\left(w-x_{0}\right) / V$. Given $t_{1}$ and $\beta_{\mathrm{m}}, t_{2}$ is defined by $\beta\left(t_{2}\right)=\beta_{\mathrm{m}}$ in Eq. 9. The velocity gradient $L$ as a function of $\beta(t)$ is:

$$
L(t)=\frac{\cos ^{2} \alpha}{t_{n}}\left[\begin{array}{ccc}
\frac{\sin 2(\alpha+\beta(t))}{2} & -\cos ^{2}(\alpha+\beta(t)) & 0 \\
\sin ^{2}(\alpha+\beta(t)) & -\frac{\sin 2(\alpha+\beta(t))}{2} & 0 \\
0 & 0 & 0
\end{array}\right]
$$

The symmetric part of $L$ is the strain rate $D$ and skew part is the spin $W$, which are:

$$
D(t)=\frac{\cos ^{2} \alpha}{2 t_{n}}\left[\begin{array}{ccc}
\sin 2(\alpha+\beta(t)) & -\cos 2(\alpha+\beta(t)) & 0 \\
-\cos 2(\alpha+\beta(t)) & -\sin 2(\alpha+\beta(t)) & 0 \\
0 & 0 & 0
\end{array}\right]
$$




$$
W=\frac{\cos ^{2} \alpha}{2 t_{n}}\left[\begin{array}{ccc}
0 & -1 & 0 \\
1 & 0 & 0 \\
0 & 0 & 0
\end{array}\right]
$$

At each time step, $L$ is updated according to Eq. 10 and used as input into the polycrystal model VPSC for texture evolution. The values of $L$ are the highest when $\beta_{\mathrm{m}}=0^{\circ}$, which corresponds to simple shearing, and the lowest when $\beta_{\mathrm{m}}=\beta_{\max }$. From Eqs. 7 and $10, L$ in the case of ideal simple shearing, $\beta_{\mathrm{m}}=0^{\circ}$, is:

$$
L=\frac{\cos ^{2}\left(\frac{\pi-\Phi}{2}\right)}{t_{n}}\left[\begin{array}{ccc}
\sin \Phi & \cos \Phi-1 & 0 \\
\cos \Phi+1 & -\sin \Phi & 0 \\
0 & 0 & 0
\end{array}\right] \quad \text { (ideal simple shearing) }
$$

When $\beta_{\mathrm{m}}>0^{\circ}$, however, the components of $L$ become functions of several parameters, $\beta_{\mathrm{m}}, V, x_{0}$, and $w$, and changes in these parameters can impact texture evolution. $\beta_{\mathrm{m}}$ affects texture evolution directly by changing the relative values of the components with respect to each other. It was first shown in [35] that increasing $\beta_{\mathrm{m}}$ rotates the texture counter-clockwise about the TD axis $[2,35,36]$. $\beta_{\mathrm{m}}$ can also have secondary effects on the intensity of some texture components. Factors like $V, x_{0}$, and $w$ multiply $L$ and thus affect all the components equally. They affect the effective strain rate, which can, in turn, alter the hardening rates of individual slip modes in hep metals, such as basal, prismatic, and pyramidal slip. Each mode may respond differently to changes in strain rate, which could lead to transitions in the predominant deformation mechanism, from say slip to twinning or from one slip mode to another. Such changes will result in substantial modifications to texture evolution.

In this work, we apply the ideal fan assumption but it is important to mention that in certain conditions, the ideal fan representation can break down. FEM calculations show that the fan may be skew [36-38], $\beta_{\mathrm{m}}$ can vary across the sample thickness [36], or the flow of the lower portion of the billet deforming near a rounded outer corner of the die occurs primarily by rigid body rotation and not shearing [36,39]. The fan model has been extended for such cases in $[35,40]$. Accounting for these deviations become important when the deformation is inhomogeneous [36,41] and in the texture evolution of route $\mathrm{C}[2,14,40]$.

\section{Modeling the ECAE routes}

In ECAE, the billet cross section does not change shape and so the extrusion can be repeated multiple times. Through this multi-step process, the billet can accumulate hundreds to thousands of percent strain. Between passes, the sample must be rotated to re-align the billet axis with the axis of the entry channel. This causes straining in the billet during the subsequent pass to take place along a different path than the previous pass. The strain path change between the two consecutive passes can be altered by additionally rotating the sample about its long axis prior to each extrusion. This second rotation defines the ECAE route. Following the experimental data in Table 1, the three routes modeled in this work are route $\mathrm{A}, \mathrm{Bc}$, and $\mathrm{C}$. Route $\mathrm{A}$ involves only the mandatory rotation between passes to re-align the billet for re-insertion into the entry channel, whereas routes $\mathrm{Bc}$ and $\mathrm{C}$ involve two rotations between every pass: the first rotation in both routes is for the required realignment and the second is an optional $90^{\circ}$ turn for route $\mathrm{Bc}$ or $180^{\circ}$ turn for route $\mathrm{C}$ about the billet axis.

The method used in this work to model multi-pass ECAE processing is detailed in [42]. In this method, the sample is rotated between passes (according to a given route) while the ECAE die is fixed, as in the laboratory. To simulate a rigid rotation of the billet, both the crystallographic and 
morphological (grain shape) textures are rotated relative to a fixed global coordinate system $(x-y-z$ in Fig. 2). In this way, the applied velocity gradient $L$ remains in the same global coordinate system from pass to pass. The velocity gradients presented in Eqs. 10 and 13 are expressed in the $x-y-z$ (or 1-2-3) global coordinate system.

\section{The visco-plastic self-consistent (VPSC) polycrystal model and other grain-scale models}

A few extensions have been built into the VPSC model so that it can more appropriately represent grain-scale behavior under large strains.

Grain-grain interactions. Grains of similar orientation in a polycrystalline metal can deform differently due to the effect of local interactions with their specific grain neighborhood. Some authors have directly modeled local grain-grain interactions in ECAE using three-dimensional finite element models employing a crystal plasticity formulation, called crystal plasticity finite element CPFE [43]. It was shown in [43] that grain-grain interactions lowered texture intensities in comparison with those predicted by standard polycrystal models.

As described earlier, VPSC accounts for the interactions between a grain and its neighborhood through an interaction equation relating the individual grain response with the response of an effective medium. The effective medium is the same for every grain and hence grains of similar orientation will deform in the same way. To model the effects of a local neighborhood, Tomé et al. [44] proposed a co-rotational (CR) scheme to force paired grains to co-rotate during deformation. In this scheme, each grain is randomly assigned a different neighbor with whom it is forced to reorient in the same way. As a result of CR, two grains of similar orientation will follow different reorientation paths because they have been assigned different neighbors. Calculated texture evolution slows down. A few ECAE studies using VPSC with the CR scheme [45-47] have shown that the texture intensities with the CR scheme become consistent with measurement up to several passes. Texture components do not change, only the dispersion of orientations about them. For one pass, VPSC with the CR scheme provided similar results to those from CPFE [43].

Grain-splitting. Grain shape can evolve differently from grain to grain depending on their anisotropy and orientation and on average grain shape can depend on pass number and ECAE route. Such differences in grain shape evolution can, in principle, affect texture evolution. Extreme grain shapes or neighbors with extreme shapes may affect a grain's ability to reorient in deformation compared to equi-axed shapes. Grain stress and interactions with neighboring grains change with grain shape, which in turn, impact grain re-orientation by changing the number and type of activated systems.

In the VPSC model, grains are calculated to have uniform internal stress states. Because of this, problems may arise when applying VPSC to ECAE. Depending on the route, pass number, and material, there are certain conditions in which grains are calculated to become severely distorted, for example, after three to four passes of route A [32]. In this event, the grain stress is not uniform within a single grain. Forcing uniformity in extremely distorted grain shapes can lead to calculated stress states which differ significantly from the actual one. Rather in actuality, a distorted grain is composed of smaller regions of uniform stress and orientation, which can differ in morphology from that of the grain. For instance, these uniform regions could be equi-axed while the parent grain is highly elongated. As discussed in the preceding paragraph, assuming the wrong shape for the uniformly stress inclusions can lead to errors in texture calculations. To alleviate these problems in ECAE process modeling, the grain splitting scheme was introduced [42]. In this scheme, ellipsoidal grains are subdivided according to the length ratios of the long $(L)$, medium $(M)$ and short $(S)$ axes of the ellipsoidal grain in comparison with a critical value $R$. As illustrated in Fig. 3, when a grain distorts into a cigar-like shape (i.e., $L / S \geq R$ and $M / S<R / 2$ ), a grain is divided into two grains. When it flattens, instead, into a pancake-like shape (i.e., $L / S \geq R$ and $M / S \geq R / 2$ ), it is subdivided into four grains. The crystallographic orientation immediately before and after the split remains the same. 
(a) Elongated grain, one split

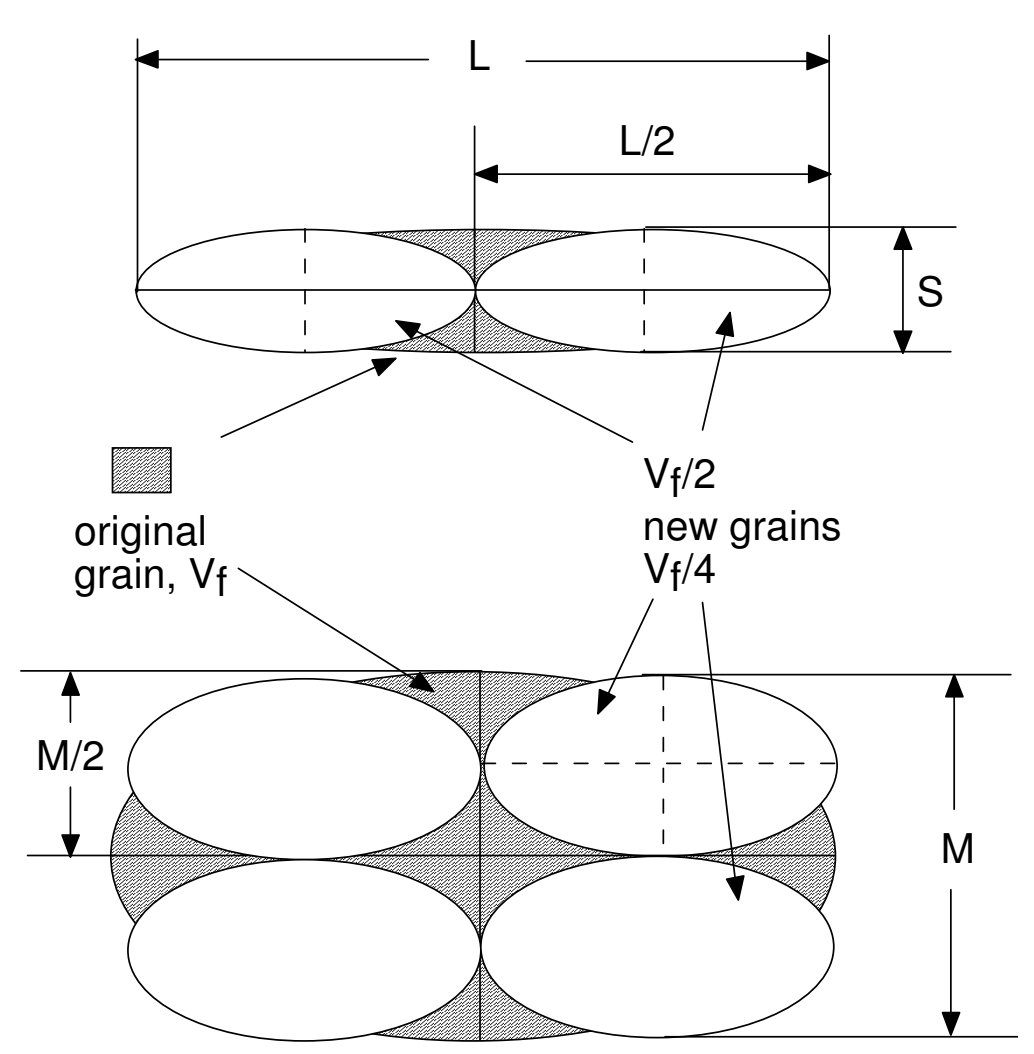

(b) flat ellipsoid, two splits

Figure 3. Grain subdivision scheme for splitting (a) elongated grains into two or (b) flat grains into four smaller inclusions

We would like to emphasize that the grain-splitting routine is not intended to model grain refinement by the formation of subgrain dislocation structures and the evolution of misorientations between them. It should be used to properly model the evolution of the shape of elements of nearly uniform stress in large strain deformation. The effect of grain shape in modeling ECAE texture evolution has been studied in Beyerlein et al. [2,42], Signorelli et al. [47], Li et al. [45], and Nazarov and co-workers [48,49]. As discussed in [4,42], $R$ is a material-dependent parameter, since some materials are more likely to contain highly distorted grains than others after SPD.

Deformation twinning. For grains that twin, a composite grain (CG) model is used to account for crystallographic reorientation by twinning [50]. The first twin system in each grain to exceed a total twin fraction of 0.05 is considered the predominant twin system PTS. The PTS is then represented by $n$ lamella reoriented to twin orientation. Once reorientation has occurred, the composite grain is treated as two separate inclusions where the inclusion shapes are given by the CG model. Therefore, while they are decoupled mechanically, they are coupled morphologically; that is, as the twin grows, the matrix shrinks. Within these twinned domains, dislocation glide and twin propagation are allowed. In the following calculations, $n=4$.

\section{Dislocation density based hardening law for slip in hep metals}

The resistance to slip $\tau_{c}^{\alpha}$ for each slip system in each slip family $\alpha$ is calculated from a recently developed single crystal hardening law for hep metals [23]. In this model, slip is treated as a thermally activated mechanism. The physical assumptions underlying this formalism apply for 
strain rates in the range of $10^{-4} / \mathrm{s}$ to $10^{3}-10^{4} / \mathrm{s}$. Each slip system $s$ in family $\alpha$ is assigned the same slip resistance $\tau_{c}^{\alpha}$ :

$$
\tau_{c}^{\alpha}=\tau_{0}^{\alpha}+\tau_{\text {for }}^{\alpha}+\tau_{\text {sub }}^{\alpha} \quad s \in \alpha
$$

The first component in Eq. 14, $\tau_{0}^{\alpha}$, is the initial resistance, composed of a constant friction stress $\tau_{0, f}^{\alpha}$ and grain size dependent Hall-Petch term $\tau_{0, H P}^{\alpha}$ :

$$
\tau_{0}^{\alpha}=\tau_{0, f}^{\alpha}+\tau_{0, H P}^{\alpha}
$$

where

$$
\tau_{0, H P}^{\alpha}=\mu H^{\alpha} \sqrt{\frac{b^{\alpha}}{d_{g}}}
$$

where $b^{\alpha}$ is the magnitude of the Burgers vector of an $\alpha$-type dislocation, $d_{\mathrm{g}}$ is the grain size, $\mu$ is the effective shear modulus, and $H^{\alpha}$ is a constant for slip mode $\alpha . \tau_{0}^{\alpha}$ does not evolve with strain and represents the resistance to propagation apart from dislocation interactions. The next two terms in Eq. 14, $\tau_{\text {for }}^{\alpha}$ and $\tau_{\text {sub }}^{\alpha}$, represent contributions from dislocation interactions and evolve with strain. $\tau_{f o r}^{\alpha}$ is related to obstacles of stored 'forest' dislocations with density $\rho_{\text {for }}^{\alpha}$ by a Taylor law:

$$
\tau_{\text {for }}^{\alpha}=b^{\alpha} \chi \mu \sqrt{\rho_{f o r}^{\alpha}}
$$

where $\chi$ is the dislocation interaction parameter $\left(\chi=0.9\right.$ in this work). $\rho_{\text {for }}^{\alpha}$ evolves with strain $\gamma^{\alpha}$ according to $[51,52]$ :

$$
\frac{\partial \rho_{f o r}^{\alpha}}{\partial \gamma^{\alpha}}=k_{1}^{\alpha} \sqrt{\rho_{f o r}^{\alpha}}-k_{2}^{\alpha}(\dot{\varepsilon}, T) \rho_{f o r}^{\alpha}
$$

$k_{1}^{\alpha}$ is a rate-insensitive coefficient for dislocation storage by statistical trapping of gliding dislocations by forest obstacles. $k_{2}^{\alpha}$ is a rate-dependent coefficient for dynamic recovery by thermally activated mechanisms (e.g., cross-slip):

$$
\frac{k_{2}^{\alpha}(\dot{\varepsilon}, T)}{k_{1}^{\alpha}}=\frac{\chi b^{\alpha}}{g^{\alpha}}\left(1-\frac{k T}{D^{\alpha} b^{3}} \ln \left(\frac{\dot{\varepsilon}}{\dot{\varepsilon}_{0}}\right)\right)
$$

where $T, \dot{\varepsilon}, k, \dot{\varepsilon}_{0}, g^{\alpha}$, and $D^{\alpha}$ are temperature $(\mathrm{K})$, the effective macroscopic strain rate, Boltzman's constant, a reference strain rate $\left(\dot{\varepsilon}_{0}=10^{7} / \mathrm{s}\right)$, a normalized effective activation enthalpy, and a drag stress. 
$\tau_{\text {sub }}^{\alpha}$ represents the resistance from obstacles stored as dislocation substructures with density $\rho_{\text {sub }}$. The defect density within substructures $\rho_{\text {sub }}$ can grow to be much larger than $\rho_{\text {for }}^{\alpha}$, and the usual Taylor law may not apply. When punching through closely spaced obstacles with small separations $\Lambda$ (such as within cell walls), dislocations encounter an enhanced resistance following $\sqrt{1 / \Lambda} \log (\Lambda)[53,54]$. Because of this, $\tau_{\text {sub }}^{\alpha}$ is related to $\rho_{\text {sub }}$ by a so-called extended Taylor law.

$$
\tau_{\text {sub }}^{\alpha}=k_{\text {sub }} \mu b^{\alpha} \sqrt{\rho_{\text {sub }}} \log \left(\frac{1}{b^{\alpha} \sqrt{\rho_{\text {sub }}}}\right)
$$

where $k_{\text {sub }}=0.086$ is a numerical constant such that Eq. 20 converges to the Taylor law Eq. 17 when $\rho_{\text {sub }}$ is small ${ }^{1}$.

Note that $\rho_{\text {sub }}$ lacks the superscript ' $\alpha$ ' because it contains dislocations from all active slip dislocations in the grain. The rate of substructure development is coupled to the rate of thermally activated recovery of active $\alpha$-type dislocations via:

$$
\partial \rho_{\text {sub }}=\sum_{\alpha} q^{\alpha}\left[k_{2}^{\alpha} \rho_{f o r}^{\alpha}\right] d \gamma^{\alpha}
$$

where $q^{\alpha}$ is a rate coefficient relating the rate of recovery of $\alpha$-type dislocations to the rate of substructure dislocations. It increases with $\rho_{\text {sub }}$ via

$$
q^{\alpha}=A^{\alpha} b^{\alpha} \sqrt{\rho_{\text {sub }}}
$$

and may depend on temperature, strain level, and strain rate. For some slip families $\alpha$ and depending on the metal, $A^{\alpha}$ was found to grow proportional with temperature [23] and inversely proportional with strain rate [25]. Otherwise, it was constant. These trends imply that substructure evolution is promoted as temperatures increase and strain rates decrease.

\section{Critical threshold for twin propagation}

In the present application, all twin systems $s$ in twin family $\beta$ have the same resistance to twin propagation $\tau_{c}^{\beta} . \tau_{c}^{\beta}$ follows a different law from that for slip:

$$
\tau_{c}^{\beta}=\tau_{0}^{\beta}+\tau_{\text {slip }}^{\beta}
$$

$\tau_{0}^{\beta}$ is the resistance in a clean grain. For certain twin types, the critical stress to nucleate $\tau_{\text {nucl }}^{\beta}$ may be much higher than that to propagate $\tau_{\text {prop }}^{\beta}$. In this case, initially $\tau_{0}^{\beta}=\tau_{\text {nucl }}^{\beta}$ and exponentially drops to $\tau_{\text {prop }}^{\beta}$ as either dislocation density [23], internal stress, or strain increases.

In addition to $\tau_{0}^{\beta}$, stored $\alpha$-type dislocations $\rho_{\text {for }}^{\alpha}$ can hinder twin propagation, increasing the resistance by $\tau_{\text {slip }}^{\beta}$, where

\footnotetext{
${ }^{1}$ Because Eq. 20 can be universally applied to both large and small values of $\rho$, it can alternatively be used for both $\tau_{\text {for }}$

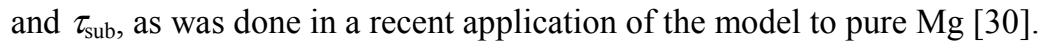




$$
\tau_{\text {slip }}^{\beta}=\mu \sum_{\alpha} C^{\beta \alpha} b^{\beta} b^{\alpha} \rho_{f o r}^{\alpha}
$$

In Eq. $24, b^{\beta}$ is the Burgers vector of the twinning dislocation and $C^{\beta \alpha}$ is a slip-twin interaction parameter. A non-zero $C^{\beta \alpha}$ implies that stored dislocations in slip family $\alpha$ hinder growth of $\beta$-type twins. $C^{\beta \alpha}=0$ implies no debilitating interaction.

\section{Model input}

Initial texture. Figure 1 shows the basal pole figures of the measured initial textures. The viewpoint corresponds to the sample orientation when it is first inserted into the entry channel. The 1-2-3 axes shown correspond to the $x-y-z$ axes in Fig. 2. The 2-axis is parallel to the entry channel and the 3-axis lies normal to the plane of the die. Each texture is represented by 1944 discrete orientations each with a given volume fraction for input into the model. Be had a weak initial texture, in which the basal poles were weakly aligned with the billet axis or 2-axis in the orientation shown in Fig. 1a. In contrast, $\mathrm{Zr}$ had a strong initial texture. As shown, $\mathrm{Zr}$ samples were inserted in one of two ways, with basal poles either parallel to the 3-axis (Fig. 1b) or to the 1-axis (Fig. 1c).

Velocity gradient. $\beta_{\mathrm{m}}$ has a complex relationship with material flow stress and hardening, die surface friction, and tool geometry. Generally it is found to increase with strain hardening, die angle $\Phi$ and outer corner angle $\Psi$. Because of the sharp corners $\left(\Psi=0^{\circ}\right)$ and efforts made to achieve frictionless surface conditions, $\beta_{\mathrm{m}}$ is expected to be small in our case and we set $\beta_{\mathrm{m}}=18^{\circ}$ for $\Phi=90^{\circ}$ and $0^{\circ}$ for $\Phi=120^{\circ}$. For $\Phi=90^{\circ}$, a PDZ $\left(\beta_{\mathrm{m}}=18^{\circ}\right)$ is considered to develop when the material is strain hardening. Otherwise when strain hardening is negligible or the material is softening, then simple shear $\left(\beta_{\mathrm{m}}=0^{\circ}\right)$ is assumed. To calculate the velocity gradient Eq. 10 for both $\beta_{\mathrm{m}}=18^{\circ}$ and $\beta_{\mathrm{m}}=0^{\circ}$, a point in the center of the sample $x_{0}=0.5$ is taken for the calculation of $t_{\mathrm{n}}$ (Eqs. 10 and 13). For the four sets of $w$ and $V$ listed in Table $1, t_{\mathrm{n}}=2 \mathrm{~s}, 1 \mathrm{~s}, 1 \mathrm{~s}$, and 423.3s, respectively.

Grain shape. The initial grain shape was spherical with diameter $d_{g}=25 \mu \mathrm{m}$ (see Table 1). The shape of each grain was allowed to evolve according to its orientation and plastic anisotropy and the grain splitting scheme with $R=4$ is invoked. Accordingly the criterion for splitting is based on the grain's individual deformation history and may occur any time and as many times as necessary during the multi-pass process.

Single crystal hardening law. Parameters for the model are material specific and have been previously characterized for the same materials studied here. In these works [21,25], a single set of parameters produced stress-strain curves and textures in agreement with a large suite of mechanical test data, involving uni-axial straining in different loading directions. The parameters for Be were also characterized for a wide range of strain rates, from $10^{-4} / \mathrm{s}$ to $5000 / \mathrm{s}$ and two different starting textures $[25]^{2}$. There it was found that $\tau_{0, f}^{\alpha}$ and $\tau_{0, H P}^{\alpha}$ were insensitive to strain rate. Table 2 summarizes the parameters for Be for only those modes relevant for the present simulations: basal slip $(\alpha=1)\{0001\}<11 \overline{2} 0>$, prismatic slip $(\alpha=2)\{10 \overline{1} 0\}<11 \overline{2} 0>$, and $2^{\text {nd }}$-order pyramidal $<\mathrm{c}+\mathrm{a}>\operatorname{slip}(\alpha=3)\{11 \overline{2} 2\}<11 \overline{2} \overline{3}>$. Those for $\mathrm{Zr}$ were tested against data obtained over a wide range of temperatures $77 \mathrm{~K}$ to $450 \mathrm{~K}$. Tables 3 and 4 summarize the parameters for pure $\mathrm{Zr}$, likewise, for those slip and twinning modes made available in the present simulations: basal slip ( $\alpha$ $=1)\{0001\}<11 \overline{2} 0>$, prismatic slip $(\alpha=2)\{10 \overline{1} 0\}<11 \overline{2} 0>, 1^{\text {st }}$-order pyramidal $<\mathrm{c}+\mathrm{a}>\operatorname{slip}(\alpha=3)$ $\{10 \overline{1} 1\}<11 \overline{2} \overline{3}>$, tensile twinning $(\beta=1)\{10 \overline{1} 2\}<10 \overline{1} 1>$, and compressive twinning $(\beta=2)$ $\{11 \overline{2} 2\}<11 \overline{2} \overline{3}>$.

\footnotetext{
${ }^{2}$ Tensile twinning $\{10 \overline{1} 2\}<10 \overline{1} 1>$ was also included in previous Be work because it was a dominant twin mode at room temperature.
} 
Table 2: Material parameters associated with the slip resistance for three slip families in pure beryllium.

\begin{tabular}{|l|l|l|l|}
\hline Beryllium & $\mathrm{c} / \mathrm{a}=1.568$ & $\mu=160.36 \mathrm{GPa}\left(\right.$ Temperature $\left.=425^{\circ} \mathrm{C}\right)$ \\
\hline$\alpha$ & Basal Slip & Prismatic Slip & $2^{\text {nd }}$-Pyramidal Slip \\
\hline Burgers vector $b^{\alpha}$ & $2.281 \mathrm{e}-10 \mathrm{~m}$ & $2.281 \mathrm{e}-10 \mathrm{~m}$ & $4.242 \mathrm{e}-10 \mathrm{~m}$ \\
\hline$\tau_{0, f}^{\alpha}$ & $1.00 \mathrm{MPa}$ & $5.00 \mathrm{MPa}$ & $>174.00 \mathrm{MPa}^{3}$ \\
\hline$H^{\alpha}$ & 200 & 200 & 200 \\
\hline$k_{1}^{\alpha}$ & $2.0 \mathrm{e}+08 \mathrm{~m}^{-1}$ & $6.0 \mathrm{e}+08 \mathrm{~m}^{-1}$ & $5.0 \mathrm{e}+09 \mathrm{~m}^{-1}$ \\
\hline$g^{\alpha}$ & $1.075 \mathrm{e}-02$ & $1.075 \mathrm{e}-02$ & $1.000 \mathrm{e}-02$ \\
\hline$D^{\alpha}$ & $8 . \mathrm{e}-04 \mathrm{MPa}$ & $7 . \mathrm{e}-04 \mathrm{MPa}$ & $6 . \mathrm{e}-04 \mathrm{MPa}$ \\
\hline$A^{\alpha}$ & 0 & 5 & 0 \\
\hline
\end{tabular}

Table 3: Material parameters associated with the slip resistance for three slip families in pure zirconium.

\begin{tabular}{|l|l|l|l|}
\hline Zirconium & $\mathrm{c} / \mathrm{a}=1.594$ & \multicolumn{2}{|l|}{$\mu=33.53 \mathrm{GPa}\left(\right.$ Temperature $\left.=25^{\circ} \mathrm{C}\right)$} \\
\hline$\alpha$ & Basal Slip & Prismatic Slip & $1^{\text {st }}$-Pyramidal Slip \\
\hline Burgers vector $b^{\alpha}$ & $3.231 \mathrm{e}-10 \mathrm{~m}$ & $3.231 \mathrm{e}-10 \mathrm{~m}$ & $6.0771 \mathrm{e}-10 \mathrm{~m}$ \\
\hline$\tau_{0, f}^{\alpha}$ & $180.00 \mathrm{MPa}$ & $15.05 \mathrm{MPa}$ & $168.74 \mathrm{MPa}$ \\
\hline$H^{\alpha}$ & 100 & 100 & 170 \\
\hline$k_{1}^{\alpha}$ & $1.25 \mathrm{e}+08 \mathrm{~m}^{-1}$ & $1.25 \mathrm{e}+08 \mathrm{~m}^{-1}$ & $2.25 \mathrm{e}+08 \mathrm{~m}^{-1}$ \\
\hline$g^{\alpha}$ & $3.75 \mathrm{e}-03$ & $3.75 \mathrm{e}-03$ & $3.20 \mathrm{e}-02$ \\
\hline$D^{\alpha}$ & $3.3 \mathrm{e}-04 \mathrm{MPa}$ & $3.3 \mathrm{e}-04 \mathrm{MPa}$ & $1.0 \mathrm{e}-04 \mathrm{MPa}$ \\
\hline$A^{\alpha}$ & 0 & 0 & 0.1 \\
\hline
\end{tabular}

Table 4: Material parameters associated with the resistance to twin propagation in pure zirconium.

\begin{tabular}{|l|l|l|l|l|l|l|l|}
\hline$\beta$ & Twin & $b^{\beta}$ & $\tau_{\text {nucl }}^{\beta}$ & $\tau_{\text {prop }}^{\beta}$ & $\begin{array}{l}{ }^{1} C^{\beta \alpha} \\
\alpha=1\end{array}$ & $\alpha=2$ & $\alpha=3$ \\
\hline 1 & $\{10 \overline{1} 2\}$ & $6.326 \mathrm{e}-11 \mathrm{~m}$ & $165 \mathrm{MPa}$ & 20 & $6.0 \mathrm{e}+03$ & 0 & 600 \\
\hline 2 & $\{11 \overline{2} 2\}$ & $9.236 \mathrm{e}-11 \mathrm{~m}$ & $300 \mathrm{MPa}$ & $300 \mathrm{MPa}$ & $8.0 \mathrm{e}+03$ & $8.0 \mathrm{e}+03$ & 600 \\
\hline
\end{tabular}

\section{Results}

All pole figures will be presented in the 1-2-3 which is equivalent to the $x-y-z$ coordinate system shown in Fig. 2.

Beryllium. Figure 4a displays the measured (0002) pole figures of the Be samples processed with the $90^{\circ}$ die $[14,15]$. As shown, texture evolution depends on processing route. Textures after $1,2 \mathrm{~A}$, and $2 \mathrm{C}$ exhibit a monoclinic sample symmetry and maximum pole intensities around 3.5 to $4.0 \mathrm{mrd}$ (multiples of random distribution). The maxima, however, are located at different positions: approximately $25^{\circ}, 15^{\circ}$, and $35^{\circ}$, respectively, from the 2 -axis. After four passes of route $\mathrm{Bc}$, however, the symmetry is broken.

Figure $4 \mathrm{~b}$ examines more systematically texture evolution in route $\mathrm{Bc}$ for the $\Phi=120^{\circ}$ die up to four passes. The first-pass texture exhibits a monoclinic symmetry with a maximum pole density at $35^{\circ}$ with intensity $2.43 \mathrm{mrd}$ [15]. This symmetry is however broken by the second pass of route Bc. The third and fourth-pass textures are strikingly similar, yet different than the first and second. Compared to the $\Phi=90^{\circ}$ die fourth-pass Bc texture, the $\Phi=120^{\circ}$ die fourth-pass Bc texture is

\footnotetext{
${ }^{3}$ This value varies substantially and has been reported to be as high as $700 \mathrm{MPa}$ at $425^{\circ} \mathrm{C}$ [55].
} 
similar and differs by the expected $\sim 15^{\circ}$ rotation, i.e., $\left(\Phi_{1}-\Phi_{2}\right) / 2=\left(120^{\circ}-90^{\circ}\right) / 2[15]$. Texture intensities in all passes remain around $3 \mathrm{mrd}$.

Figures 5 and 6 show the corresponding predictions for routes A, C, and Bc. The simulation predicts most of the main components and important trends in texture evolution. For the first and second passes of routes $\mathrm{A}$ and $\mathrm{C}$ (Fig. 5), the monoclinic symmetry, the un-split maxima, and changes in the locations of the main components from one pass to another and between these two routes are predicted. The model predicts not only a second-pass route $\mathrm{C}$ texture that is different than the weak initial one, but even the low intensity components in the outer rim. Likewise, for $\Phi=$ $120^{\circ}$ route $\mathrm{Bc}$ (Fig. $6 \mathrm{a}$ ), the model was effective in predicting the observed texture evolution in each pass up to four passes. For $\Phi=90^{\circ}$ route Bc (Fig. 6b), the model predicts that the texture would evolve in an analogous manner as that for $\Phi=120^{\circ}$ : the second and third textures would not have a monoclinic symmetry, as in $2 \mathrm{~A}$ and $2 \mathrm{C}$, and the third and fourth textures would be similar.

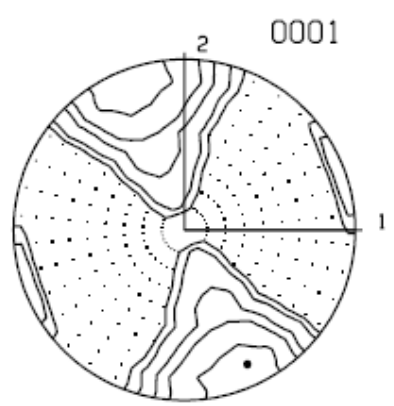

$\max =3.71$

1

(a) $\Phi=90^{\circ}$

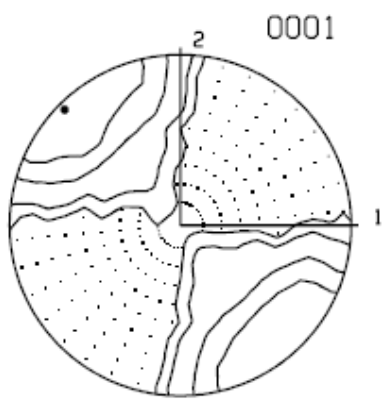

$\max =2.43$

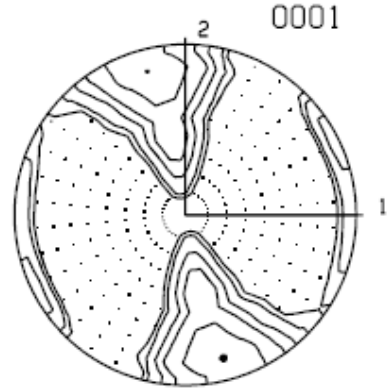

$\max =4.06$

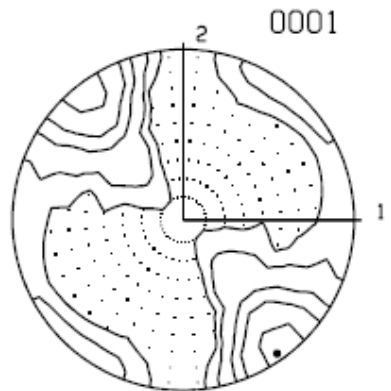

$\max =3.57$

$2 \mathrm{C}$

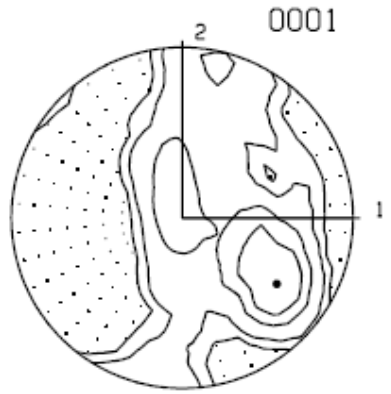

$\max =2.97$

$4 \mathrm{Bc}$
1

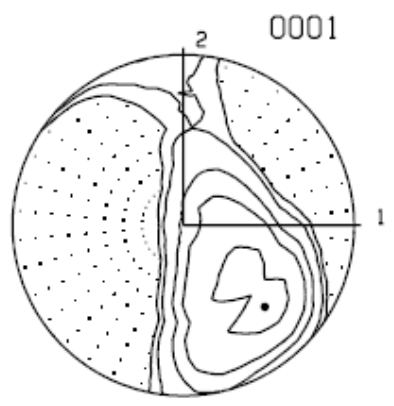

$\max =3.48$

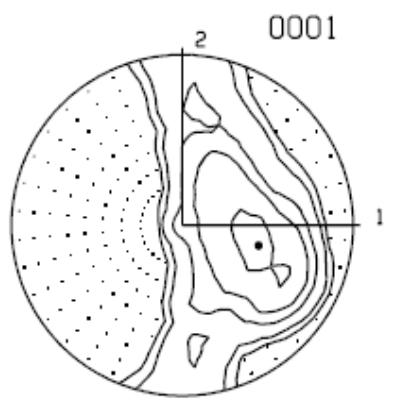

$\max =3.43$

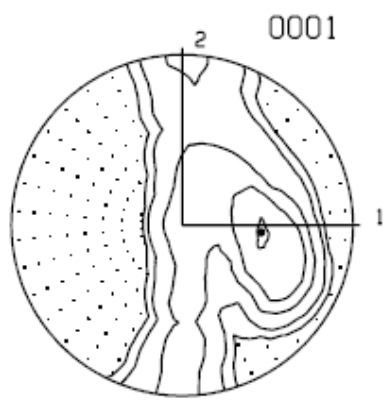

$\max =3.21$
$2 \mathrm{Bc}$

$3 \mathrm{Bc}$

$4 \mathrm{Bc}$

Figure 4. Basal pole figures of measured Be textures after ECAE using a (a) $\Phi=90^{\circ}$ die and (b) $\Phi$ $=120^{\circ}$ die. The number below each pole figure indicates the number of ECAE passes and the letter indicates the route. Contour levels: 0.8/1.0/1.5/2.0/3.0/4.0 mrd 


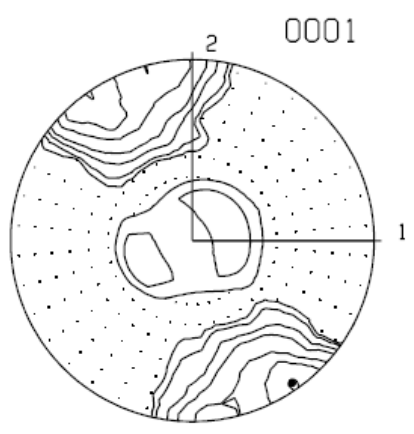

$\max =7.58$

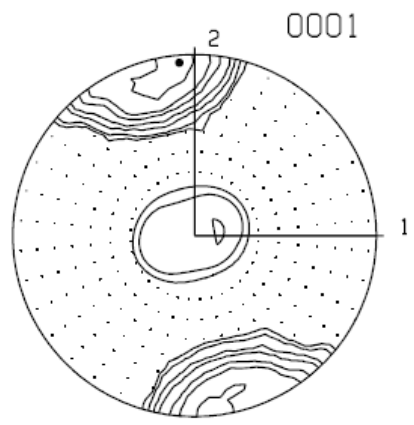

$\max =9.53$

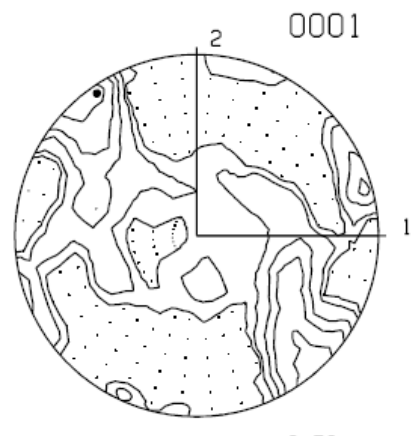

$\max =3.76$

Figure 5. Basal pole figures of predicted textures for Be and the $\Phi=90^{\circ}$ cases: (a) first pass, (b) second pass route A, and (c) second pass route C. Contour levels: 0.8/1.0/1.5/2.0/3.0/4.0/7.0/10 mrd

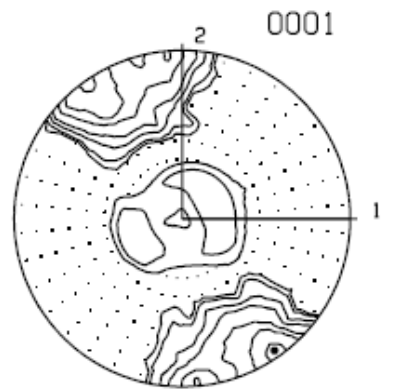

$\max =8.93$

1

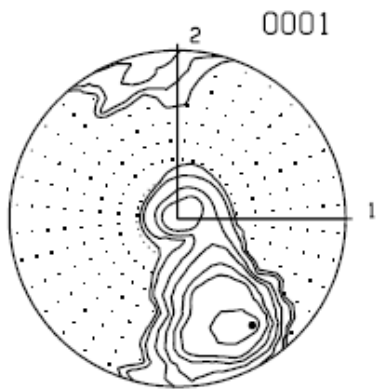

$\max =9.38$

$2 \mathrm{Bc}$

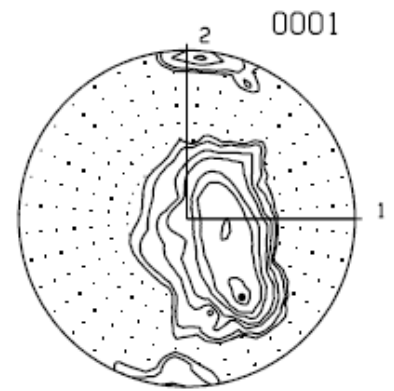

$\max =9.71$

$3 \mathrm{Bc}$

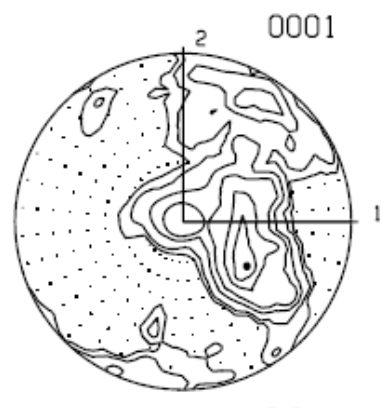

$\max =5.34$

$4 \mathrm{Bc}$

(a) $\Phi=90^{\circ}$

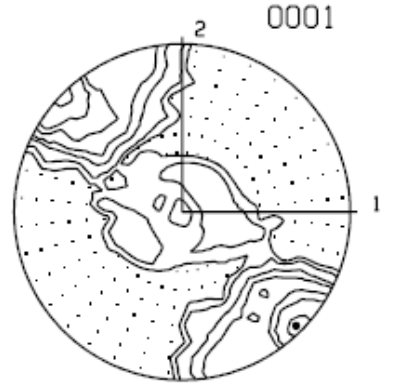

$\max =9.42$

1

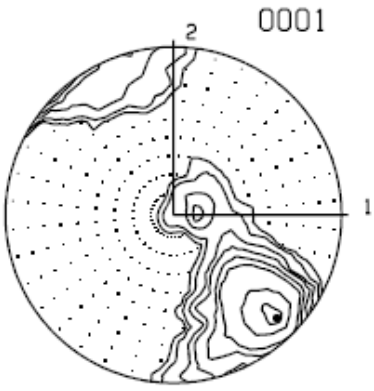

$\max =11.61$

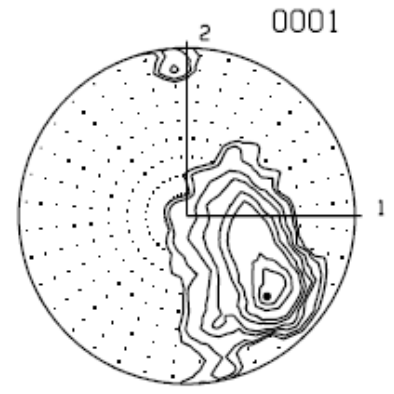

$\max =14.23$

$3 \mathrm{Bc}$

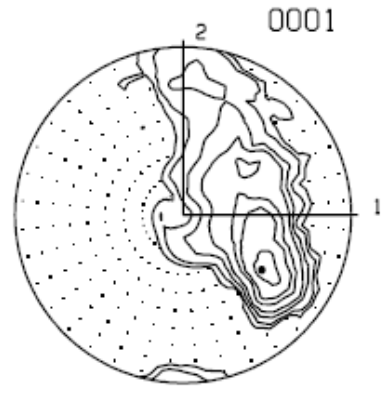

$\max =9.71$

$4 \mathrm{Bc}$

(b) $\Phi=120^{\circ}$

Figure 6. Basal pole figures showing the calculated textures for Be after one to four passes of route Bc with (a) $\Phi=90^{\circ}$ die and (b) $\Phi=120^{\circ}$ die. Contour levels: $0.8 / 1.0 / 1.5 / 2.0 / 3.0 / 4.0 / 7.0 / 10 \mathrm{mrd}$ 
Although we do not have measurements for the intermediate second and third passes, we find that the calculated fourth-pass $\mathrm{Bc} \Phi=90^{\circ}$ texture compares well with the measurement in Fig. 4a. Overall, the agreement achieved by the route Bc calculations, particularly for the third pass for $\Phi=$ $120^{\circ}$ and fourth passes for both $\Phi=90^{\circ}$ and $\Phi=120^{\circ}$, are encouraging considering the simulations were carried out continuously starting from the initial material state and this route involves substantial strain path changes.

Figure 7 shows the calculated evolution of the von Mises with strain during each pass for the $\Phi$ $=90^{\circ}$ case. This deformation response is the result of both texture evolution and material hardening in the single crystals. As shown, the material strain hardens in every pass with the exception of the second pass of route $\mathrm{C}$ and the last pass of route $\mathrm{Bc}$. Accordingly, for these two extrusions we set $\beta_{\mathrm{m}}=0^{\circ}$ and for the rest, $\beta_{\mathrm{m}}=18^{\circ}$ to obtain the predictions in Figs. 5 and 6 .

The relative $\%$ contribution of each slip mode (averaged over all grains) to polycrystalline deformation at each instant during the entire multi-pass process are calculated and presented in Figs. 8 and 9 for the $\Phi=90^{\circ}$ and $120^{\circ}$ cases. They were found to change from pass to pass and with route, as a result of both texture and single crystal hardening. In all cases, pyramidal slip activity is relatively small in the range of $0.0 \%$ to $0.03 \%$.

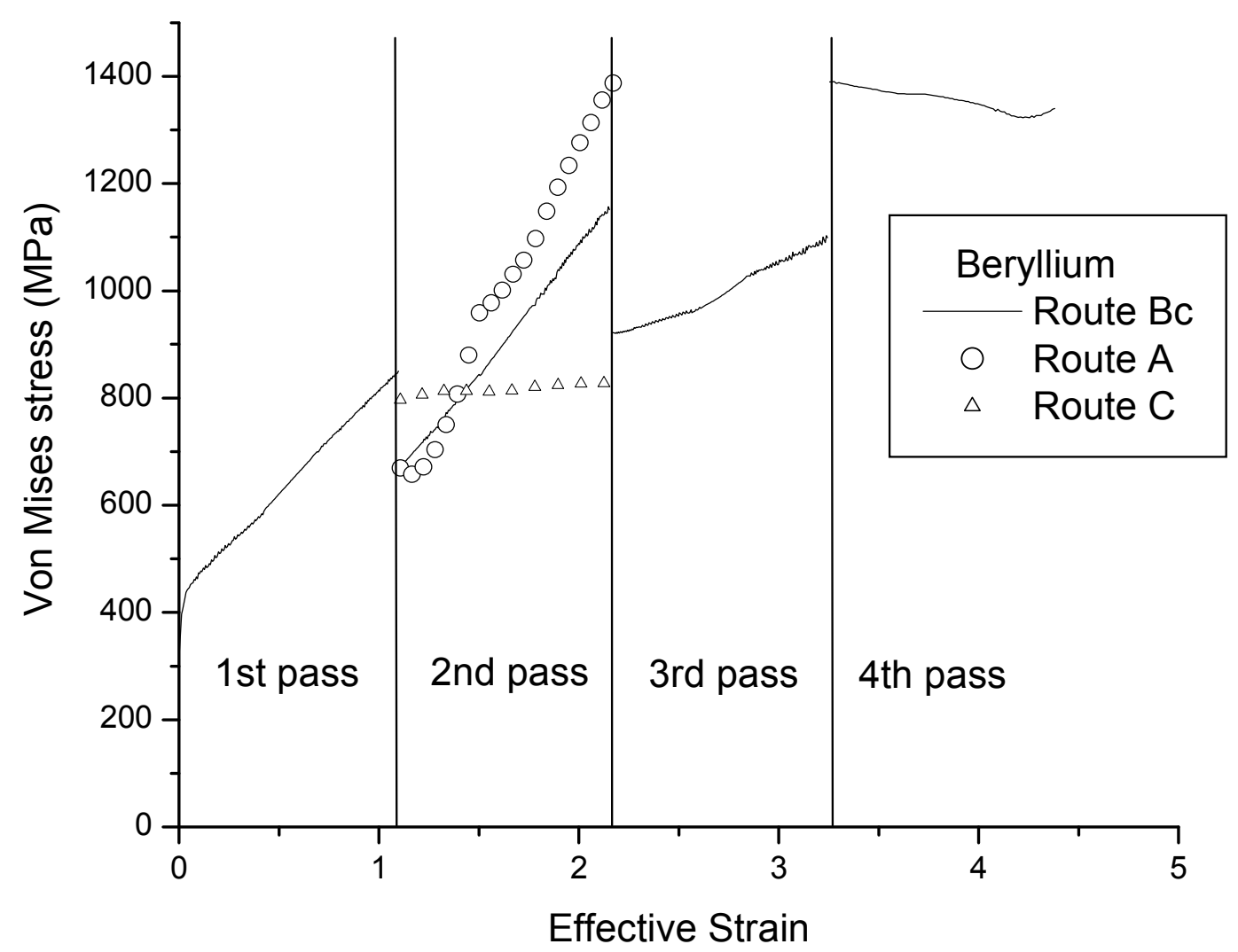

Figure 7. Calculated evolution of the von Mises stress with strain during each pass for routes A, C, and $\mathrm{Bc}$ in $\mathrm{Be}$. 


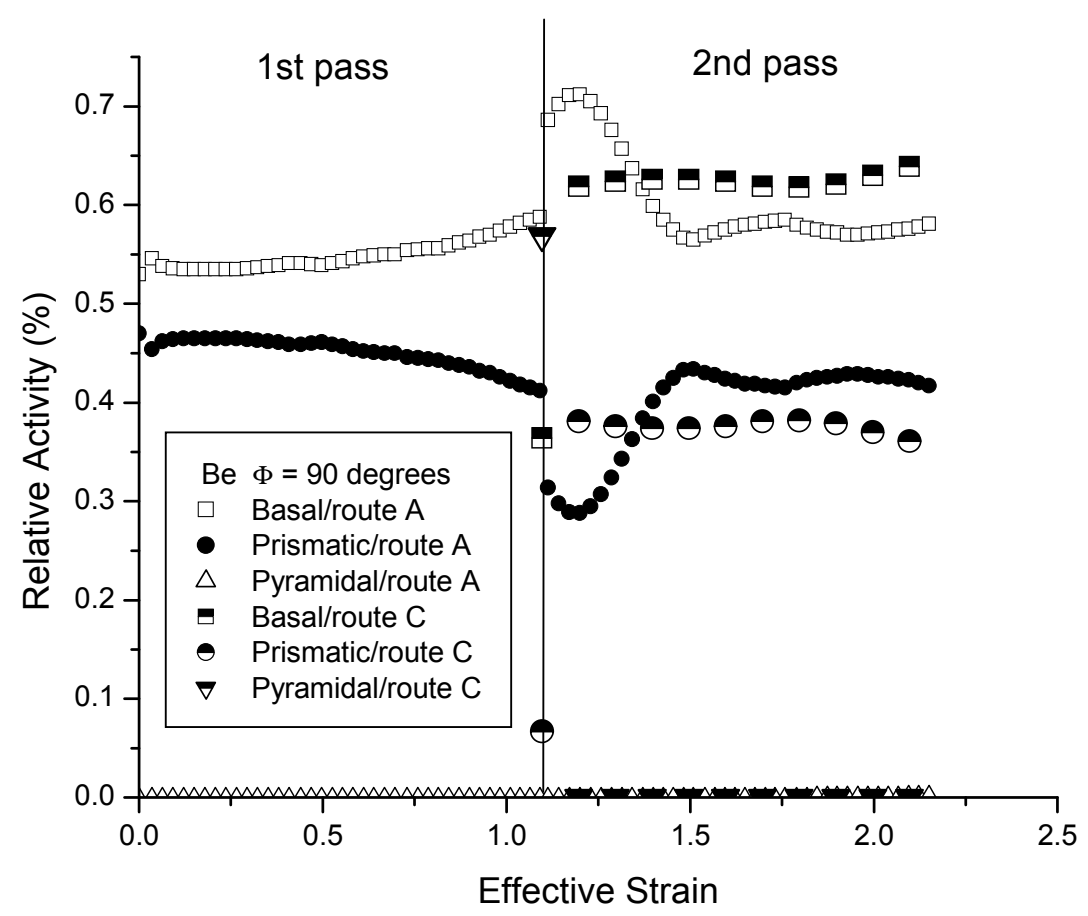

Figure 8. Predicted percent contributions of each slip mode to deformation during the first and second passes of routes A and C with $\Phi=90^{\circ}$ and Be.

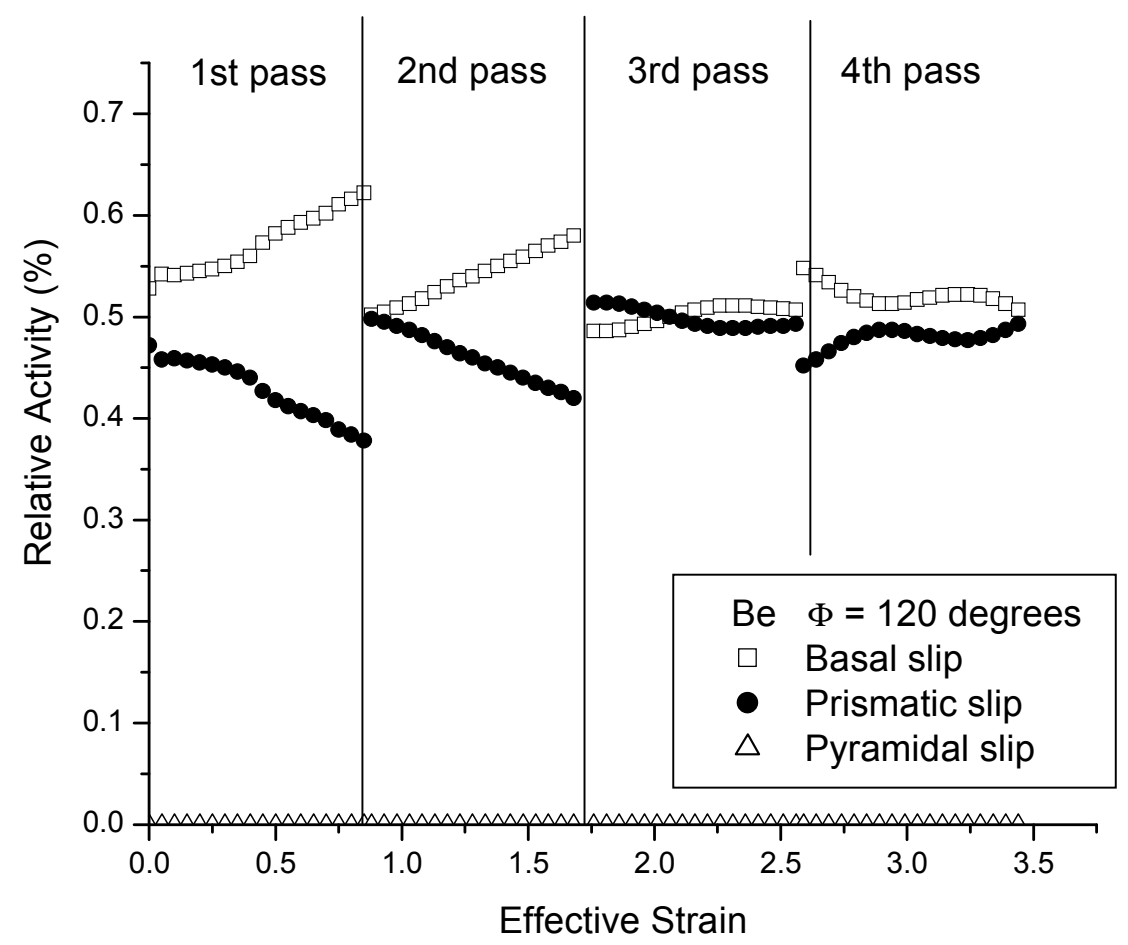

Figure 9. Predicted percent contributions of each slip mode to deformation during the first four passes of route $\mathrm{Bc}$ for a $\Phi=120^{\circ}$ die and $\mathrm{Be}$. 
In the first pass and second passes of route $\mathrm{A}$ and $\mathrm{C}$, basal slip is the most active and prismatic slip the second most active (Fig. 8). The change in texture relative to the new load path direction of the second pass is less abrupt in route $\mathrm{C}$ than route $\mathrm{A}$, and therefore, there is less transition in slip activity when going from the first to second passes.

In route $\mathrm{Bc}$, the strain path change between passes is even more disruptive. In the first pass and second pass of route $\mathrm{Bc}$ with $\Phi=120^{\circ}$, basal slip is the most active, with prismatic also providing a substantial contribution (Fig. 9). By the third and fourth passes, however, the relative contribution of prismatic slip increases. Because prismatic slip has a higher slip resistance than basal slip, its progressive increase in activity can be attributed to changes in the orientation between the strain path direction and new material texture between the first two passes and subsequent passes in route Bc processing. Consistent with the similarity in the observed textures between the third and fourth pass, the variations in basal and prismatic slip activity during the third and fourth passes are comparable. To elucidate the reason for the apparent 'saturation' in texture after pass three, Fig. 10 compares the evolution of texture during the third and fourth passes. These results reveal that the third and fourth pass textures of route $\mathrm{Bc} \Phi=120^{\circ}$ are similar because texture evolved in a similar manner during each extrusion, not because texture evolution stopped.

\section{ENTRY}

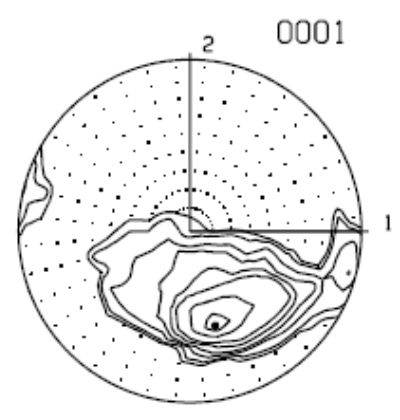

$\max =12.27$

(a) Third pass

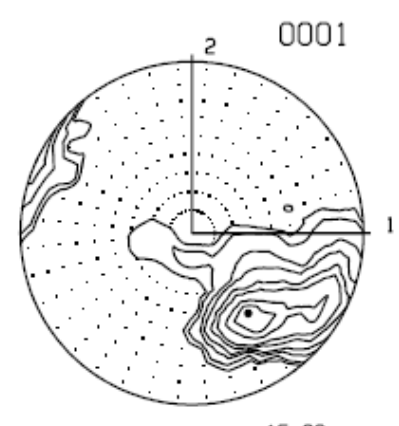

$\max =15.06$

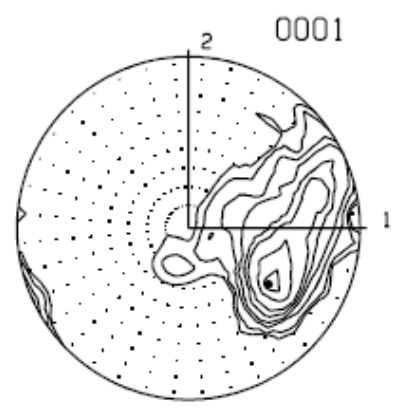

$\max =12.13$

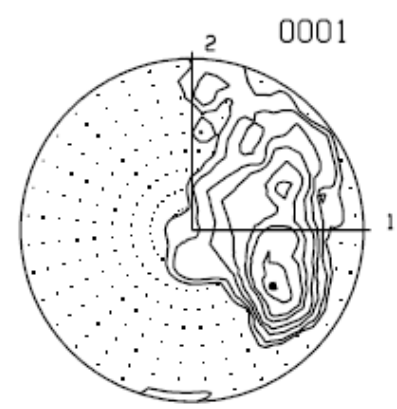

$\max =10.68$

\section{EXIT}

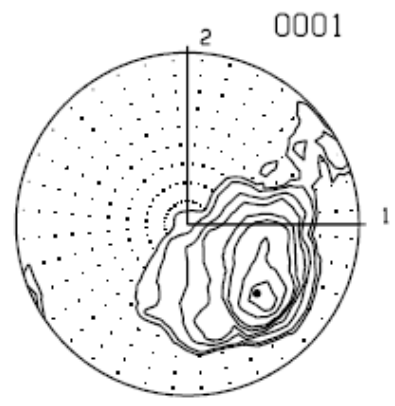

$\max =12.03$

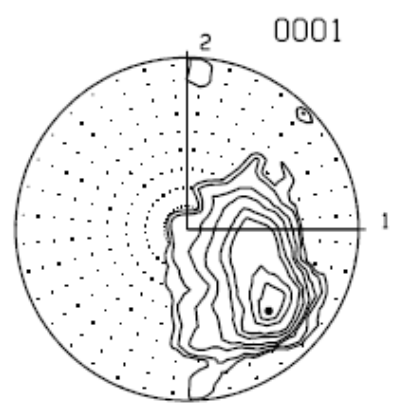

$\max =14.66$

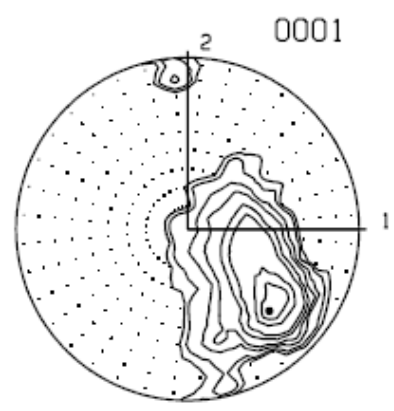

$\max =14.23$

(b) Fourth pass

Figure 10. Texture evolution in Be during the (a) third and (b) fourth pass of route $\mathrm{Bc}$ for a $\Phi=$ $120^{\circ}$ die. Pole figures correspond to (a) $E_{\mathrm{VM}}=1.72,2.05,2.38$, and 2.58 and (b) $E_{\mathrm{VM}}=2.58,2.91$, 3.24, and 3.44. Contour levels: 0.8/1.0/1.5/2.0/3.0/4.0/7.0/10 mrd 
Likewise, corresponding calculations for $\Phi=90^{\circ}$ route $\mathrm{Bc}$ in Fig. 11 suggest significant changes in slip activity from one pass to another. The most distinguishing feature of the $\Phi=90^{\circ}$ die from the $\Phi=120^{\circ}$ die is that prismatic slip dominates in the beginning of the second pass and throughout the third pass. By the fourth pass, both slip modes are more or less equally active, as in the fourth pass of the $\Phi=120^{\circ}$ die.

The difference in the predominant slip mode between the two die angles would be unexpected because for a given pass number, their final, 'exit' textures are similar. Although the 'exit' textures after each pass may be similar, the relative orientation between the 'entry' texture and the main direction of applied shearing at the start of each pass are sufficiently different between the two die angles such that the distribution of slip will not necessarily be the same. This difference is demonstrated in Fig. 12 for entry textures into the third pass. To reach a similar texture from two different starting configurations, the $\Phi=90^{\circ}$ deformation in Fig. 12a activated prismatic followed by basal slip and the $\Phi=120^{\circ}$ deformation in Fig. 12b activated basal followed by prismatic slip. This analysis demonstrates that the fact that the end textures may be the same does not mean that process by which they were obtained was the same.

For the predictions in Figs. 4-12, we used the same hardening law parameters as in [25] except for three items. First, tensile twinning was not found in ECAE samples processed at $700 \mathrm{~K}$ and therefore, it was not made available in the model. Second, the $\tau_{0, f}^{\alpha}$ values at $700 \mathrm{~K}$ are expected to be different than those characterized at 300K. Data reported in [55] for pure Be were used to obtain estimates for $\tau_{0, f}^{\alpha}$ for $\alpha=1,2$, and 3 in Table 2. Last, $A^{\alpha=2}$ as lowered from 20 to 5 , in order to lower the rate of substructure evolution contributed by prismatic slip dislocations over the large strain interval ( $\sim 300-400 \%)$ imposed by ECAE. The previous value for $A^{2}$, was characterized only for $10-20 \%$ strain at room temperature. Higher processing temperatures are not believed to be responsible for lower $A^{\alpha=2}$ used here. Instead, larger amounts of strain that promote recovery processes and slow down substructure evolution implies the need for a lower $A^{\alpha=2}$.

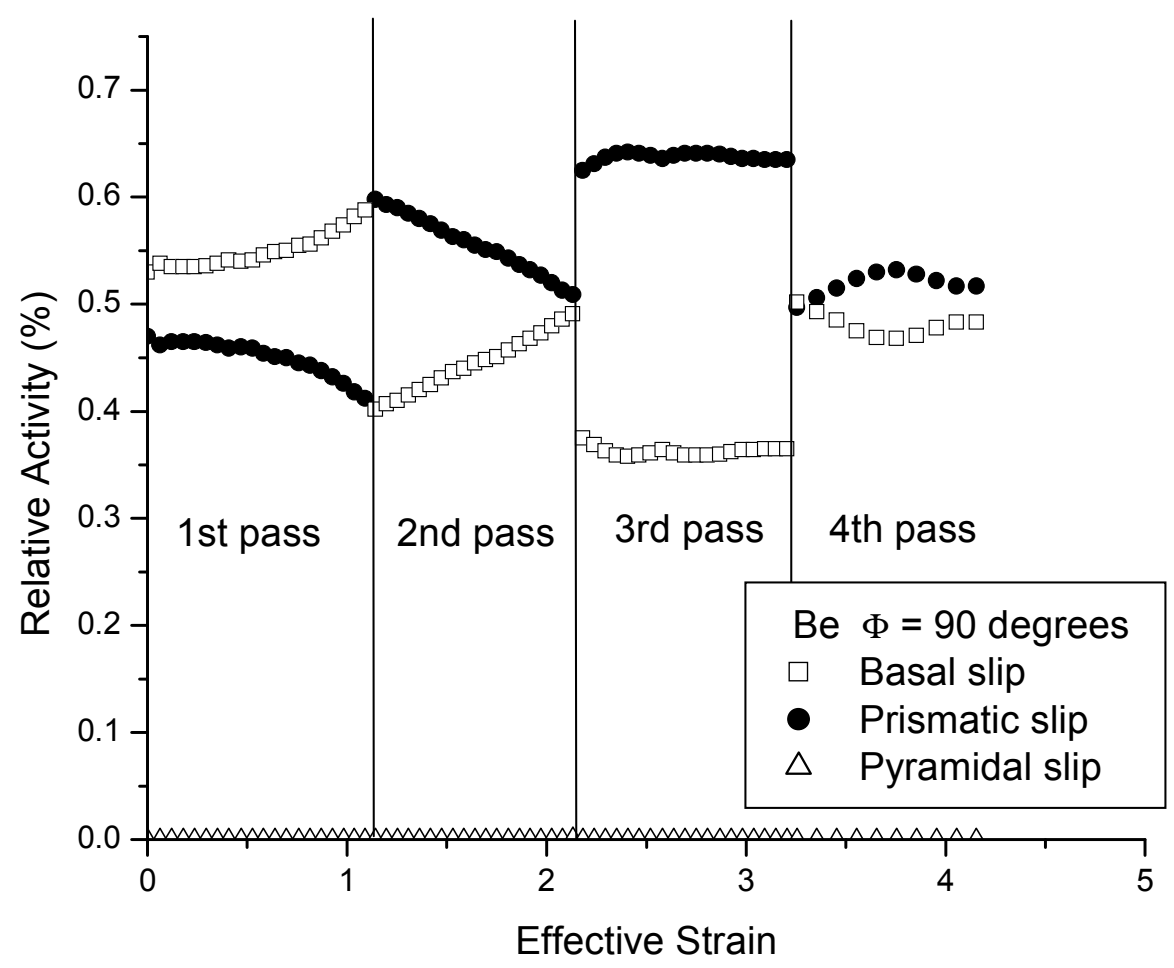

Figure 11. Predicted percent contributions of each slip mode to deformation during the first four passes of route $\mathrm{Bc}$ for a $\Phi=90^{\circ}$ die. 


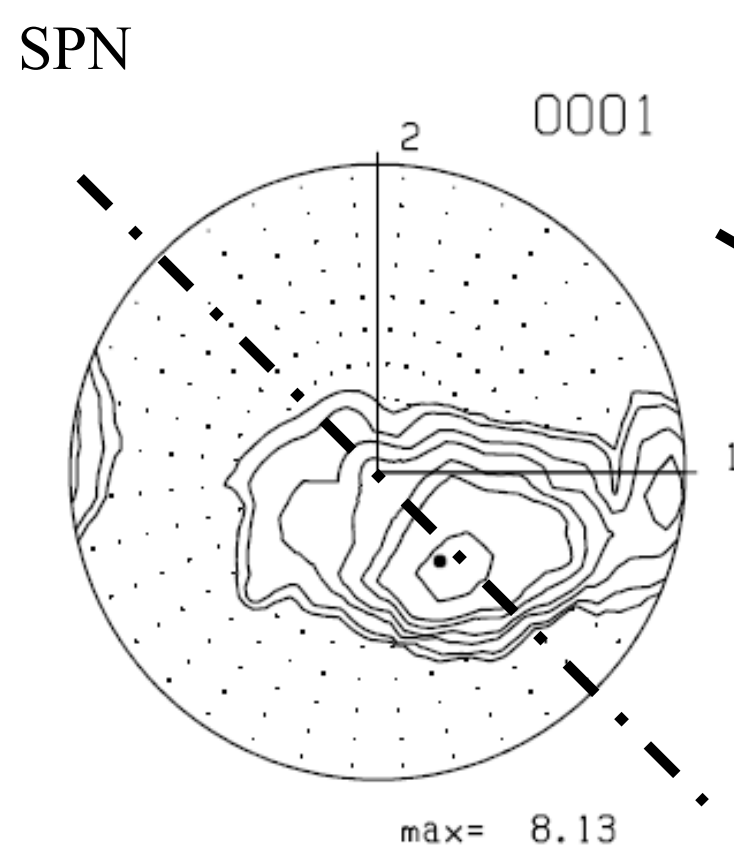

(a)

\section{SPN}

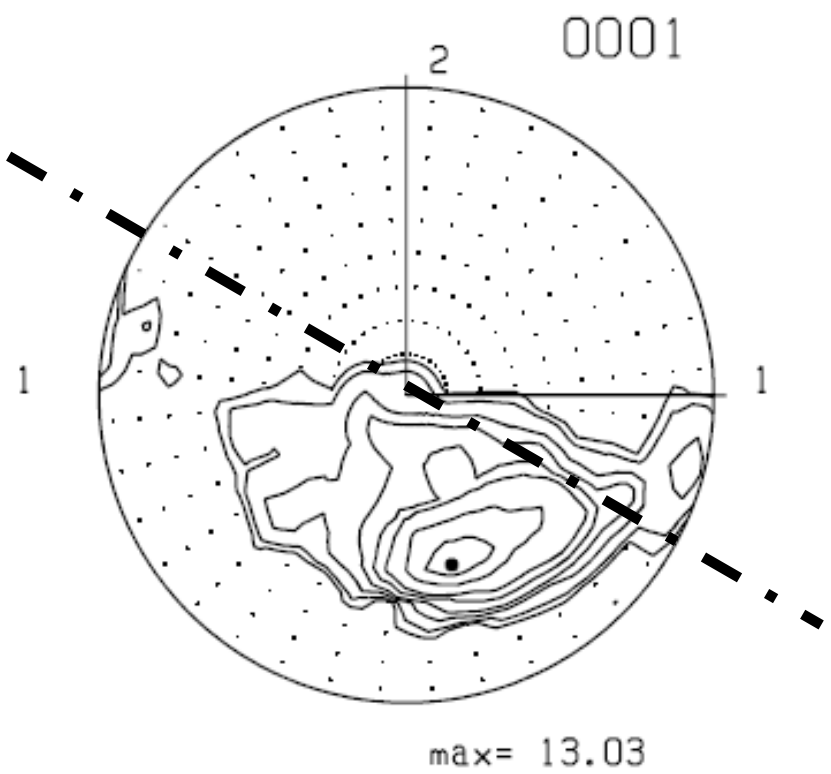

(b)

Figure 12. Comparison between the relative orientation between the shear plane and entry textures at the beginning of pass 3 for (a) a $\Phi=90^{\circ}$ die versus (b) a $\Phi=120^{\circ}$ die. The dashed line indicates the shear plane normal (SPN). Contour levels: 0.8/1.0/1.5/2.0/3.0/4.0/7.0/10 mrd

Zirconium. Figure 13 displays the measured (0002) pole figures of the one-pass $\mathrm{Zr}$ samples $\left(2^{\text {nd }}\right.$ column) for both starting configurations $\left(1^{\text {st }}\right.$ column). In both cases, one ECAE pass caused the basal poles to strongly align $\sim 25^{\circ}$ away from the 2 -axis. The concentration in this region was greater when the basal poles were initially aligned with the 1-axis (Fig. 13b), than when they were initially aligned along the 3-axis (Fig. 13a). In the latter case, the basal poles tended to be more spread out towards and along the 3-axis as well. These differences are due solely to effect of the initial distribution of basal poles. Yet, the locations of the maxima in both cases are the same as those in Be after one pass (Fig. 4a).

The similarities between the Zr first-pass textures and those of Be (Fig. 4a) indicate activation of basal slip during ECAE of Zr. However, for $\mathrm{Zr}$, only parameters for prismatic $\operatorname{slip}(\alpha=2), 1^{\text {st }}$. order pyramidal $<\mathrm{c}+\mathrm{a}>\operatorname{slip}(\alpha=3)$, and tensile twinning $(\beta=1)$ were characterized previously for the dislocation density model [23]. Because basal slip had not been reported in previous test data involving much smaller strain levels $(<25-30 \%)$, we selected parameters such that basal slip plays an active role later in the extrusion $(>15 \%)$. Note in Table 3 that the initial value $\tau_{0, f}^{\alpha}$ for basal slip $(\alpha=1)$ is larger than those for prismatic and pyramidal.

Calculation of the deformation applied to the $\mathrm{Zr}$ sample during the extrusion was complicated by the fact that the billet was a 'composite' of an $8 \mathrm{~mm} \times 8 \mathrm{~mm} \mathrm{Zr}$ specimen centered within a 25.4 $\mathrm{mm} \times 25.4 \mathrm{~mm} \mathrm{Ni}$ can [21]. After the extrusion, it was found that the thick-walled Ni sleeve allowed its $\mathrm{Zr}$ center to expand in cross-section [21]. It is unknown when exactly this expansion took place. For simplicity we assume that the Zr laterally expanded while it was being pushed in the entry channel, before it entered the corner and experienced significant shear deformation. In the model, ECAE deformation, therefore, was applied in two steps: first a relatively small uni-axial compression $(10 \%)$ and second severe shearing via the fan model with $\beta_{\mathrm{m}}=18^{\circ}$. 
Initial

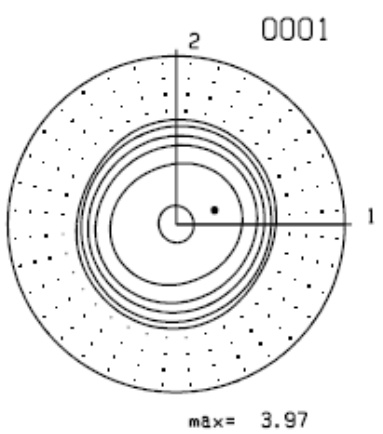

(a) Case One
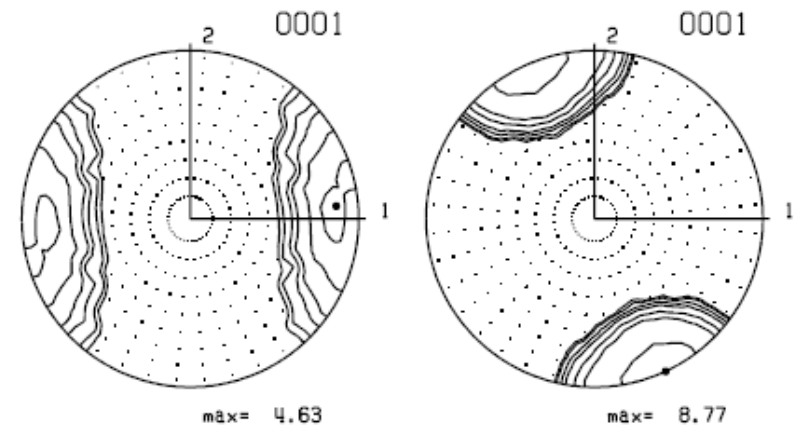

$\max =8.77$

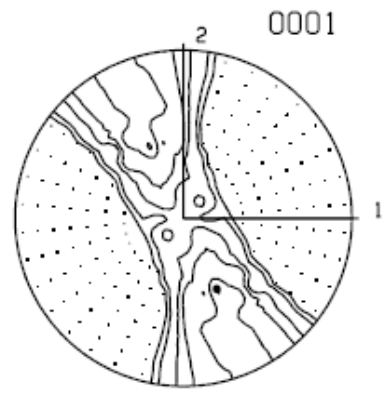

$\max =4.17$

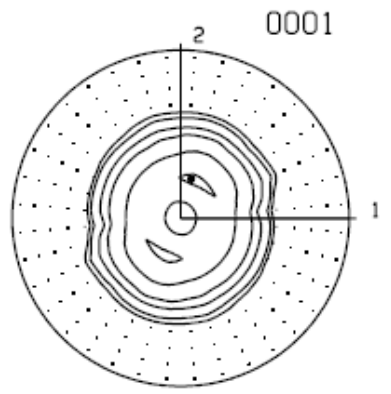

$\max =4.13$

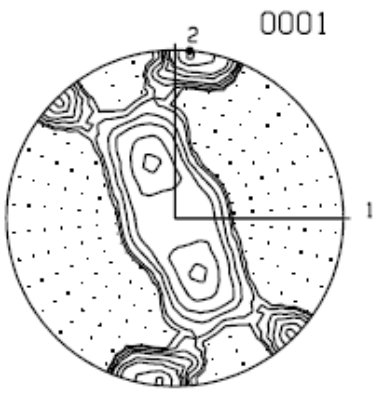

$\max =10.65$

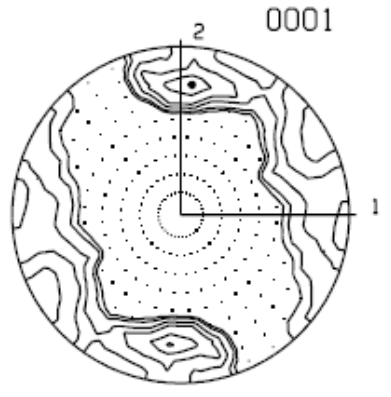

$\max =4.16$

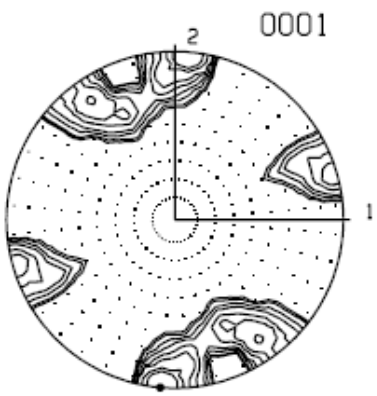

$\max =18.27$

(b) Case Two

Figure 13. Comparison of the basal pole figures of the measured and predicted $\mathrm{Zr}$ textures for (a) case one in which the basal poles were initially aligned with the 3-axis and (b) case two in which they were initially aligned with the 1 -axis. $1^{\text {st }} \mathrm{col}$ : measured textures before ECAE. $2^{\text {nd }}$ col: measured textures after ECAE. $3^{\text {rd }}$ col: Calculated textures after the initial upset compression. $4^{\text {th }}$ col: Calculated textures after one pass of ECAE. Contour levels: 0.8/1.0/1.5/2.0/3.0/4.0/7.0/10 mrd

The third and fourth columns of Fig. 13 show the predicted textures after uni-axial compression and the extrusion, respectively. The main differences in texture evolution between the two starting configurations are reasonably predicted.

The relative \% contribution of each slip mode and tensile twinning at each instant during the pressing and the accumulated twin fraction with straining are presented in Figs. 14 and 15. Comparing these two results shows that the initial configuration changed the levels of slip and twin activities during ECAE. When the basal poles are initially aligned with the 3-direction, the crystals are preferentially oriented for prismatic slip under simple shearing at the die channel intersection region. Some tensile twins developed during the initial upset, and continued to grow during the extrusion. As shown in Fig. 14a, deformation in the grain regions outside of the twins proceeds primarily by prismatic slip activity, with some relatively small amounts of basal slip, twinning and pyramidal slip activity. In contrast, when the basal poles are initially aligned with the extrusion 


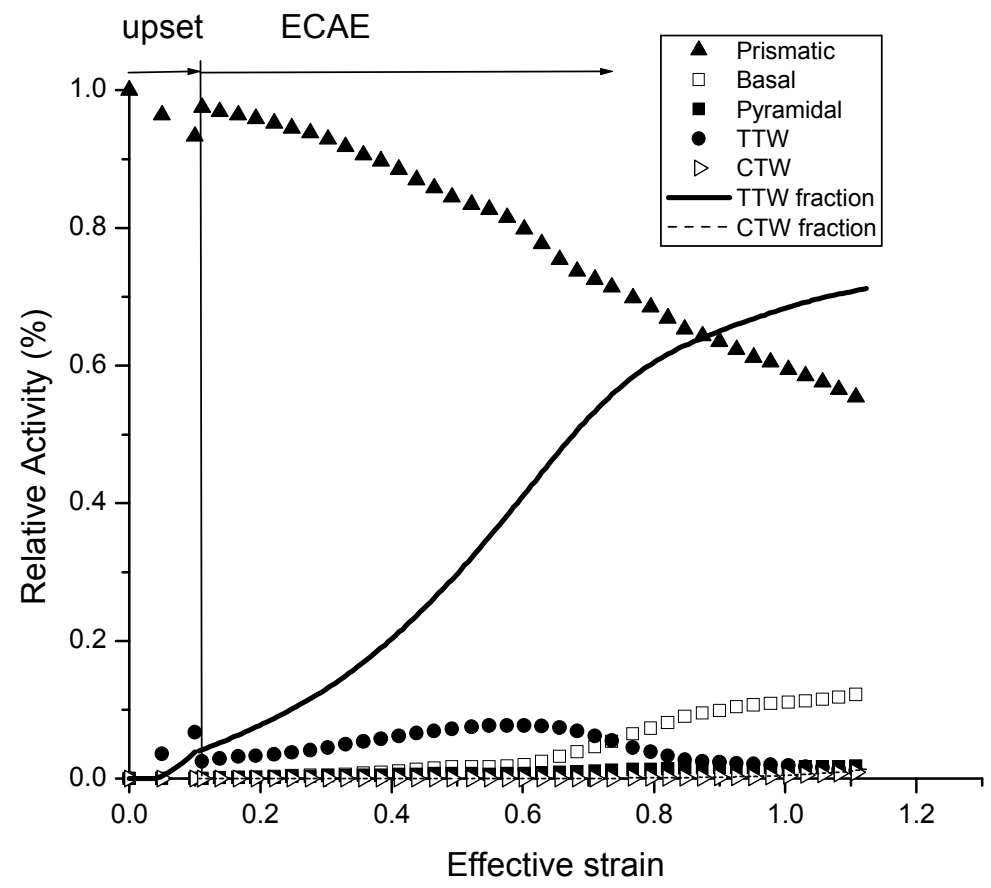

(a)

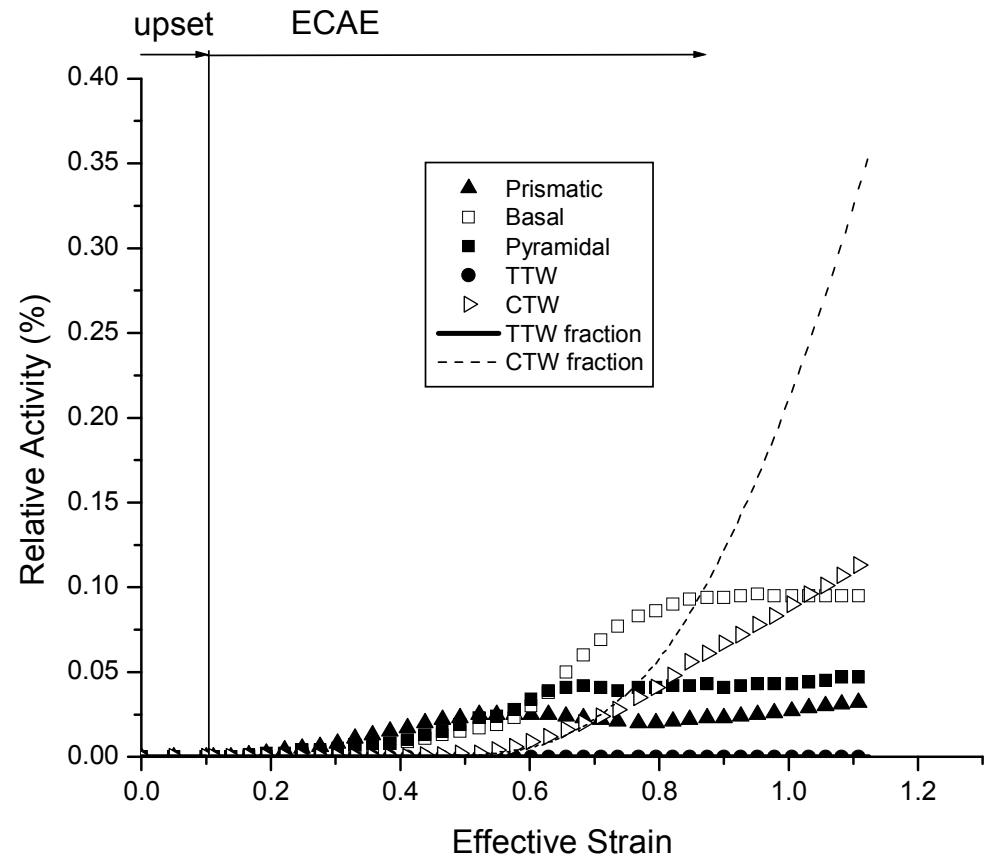

(b)

Figure 14. Predicted evolution of the activity of each slip mode to the deformation of $\mathrm{Zr}$ during the first pass (a) within the grains (outside of the twin regions) and (b) within the twinned domains for case one in which the basal poles were initially aligned with the 3-axis (see Fig. 1b). 


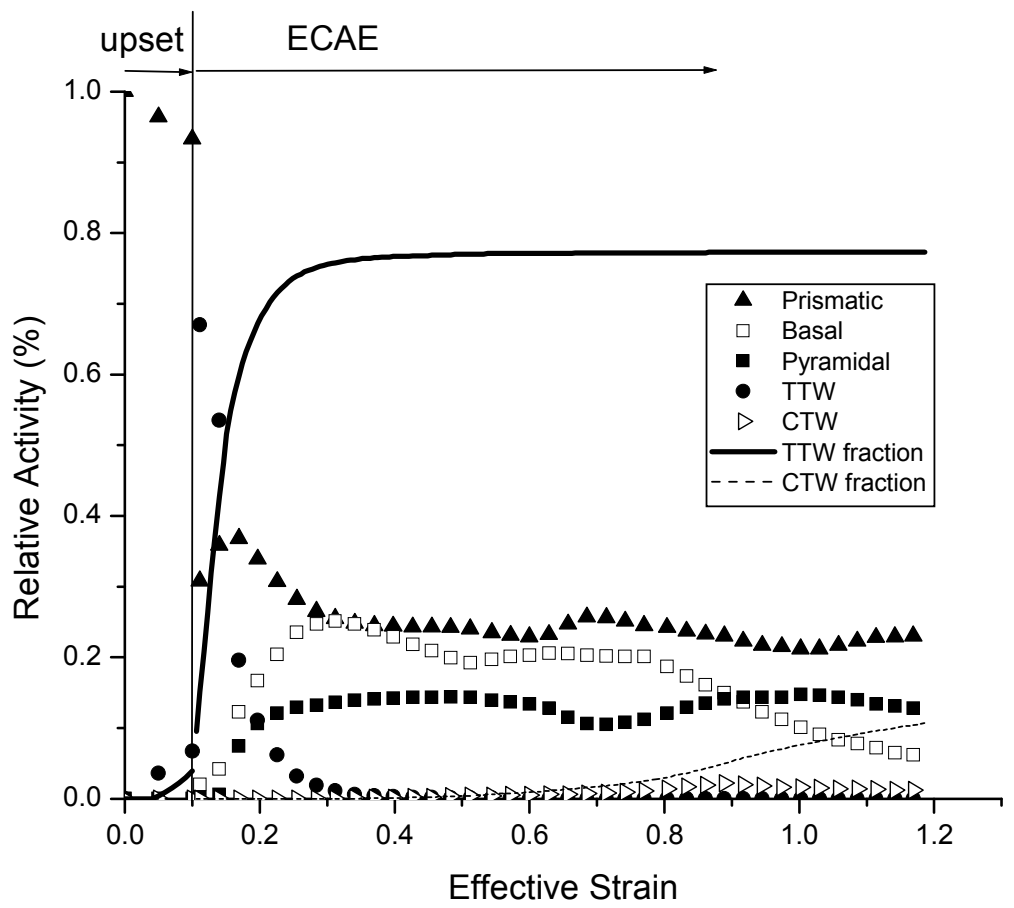

(a)

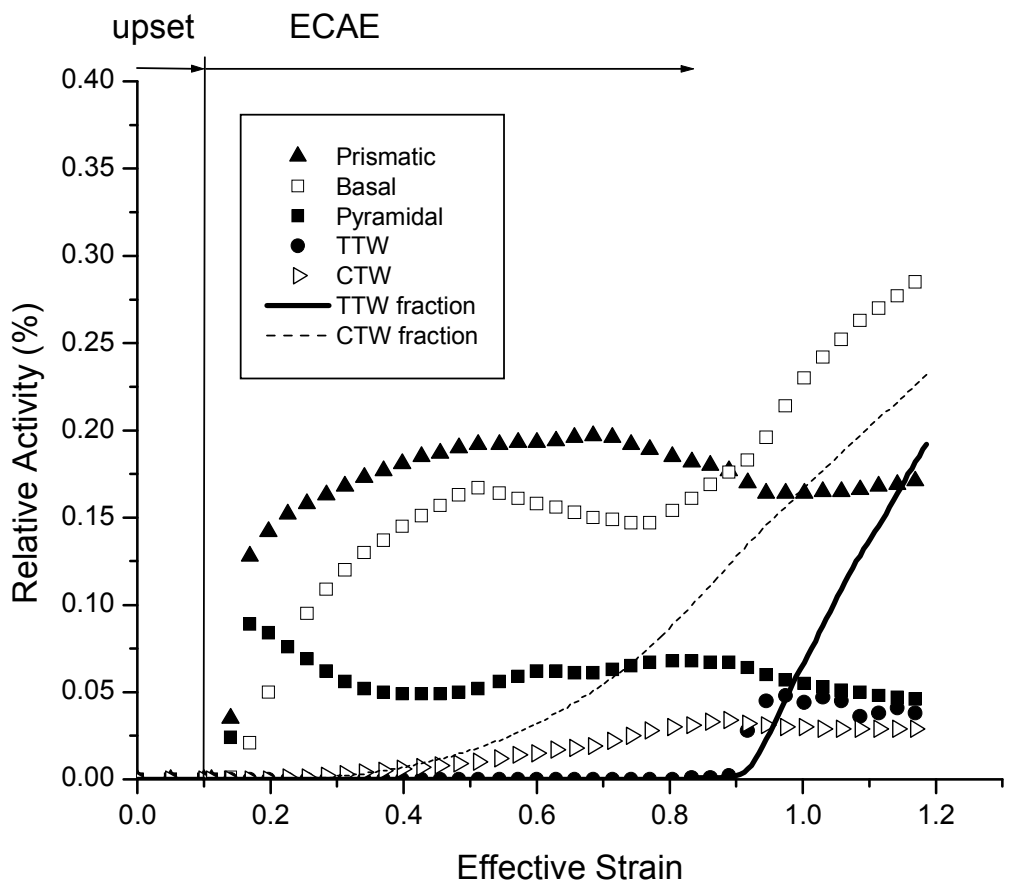

(b)

Figure 15. Predicted evolution of the activity of each slip mode to the deformation of $\mathrm{Zr}$ during the first pass (a) within the grains (outside of the twin regions) and (b) within the twinned domains for case one in which the basal poles were initially aligned with the 1-axis (see Fig. 1c). 
direction (1-axis), ECAE deformation must be accommodated by all three slip modes (Fig. 15a). During the initial compression, tensile twins developed but during the subsequent extrusion, twin activity dropped and the twin fraction saturated. Note that as we have enforced, basal slip was not active $(<5 \%$ relative activity) until after $70 \%$ strain in the first case and after $15 \%$ in the second. The lack of basal slip activity at small strain levels is consistent with our previous work involving quasi-static, monotonic deformation of $\mathrm{Zr}[23,26]$.

The results in Figs. 14a and 15a suggest that tensile twinning was prevalent in both cases, saturating at $71 \%$ in the first and $77 \%$ in the second case by the end of the extrusion. The corresponding slip and compressive twin activity within the twins is shown in Figs. 14b and 15b. In the first case (Fig. 14b), basal slip and secondary compressive twinning are the most active mechanisms in the twin domains. In the second case (Fig. 15b), both prismatic and basal slip operate within the twins. Secondary compressive and tensile twinning also occur, but to a lesser extent.

There are still some discrepancies between the texture predictions and measurement. Texture evolution is sensitive to the applied deformation and hence some of the disagreement may be due to uncertainties in the applied strain field generated in the $\mathrm{Zr}$ as a result of the relatively thick $\mathrm{Ni}$ jacket. These discrepancies, we suspect, may also be alleviated if basal slip were more active and/or twin growth were not so substantial. Regarding the former, basal slip may be favored over prismatic and pyramidal slip as a consequence of the large internal stresses and strain generated during ECAE, an issue we will address further in the discussion. Regarding the latter, the twin fractions reached in simulation are relatively high in both cases and unfortunately there is no microscopic validation for this prediction. The twinning frequency is likely over-predicted considering that substructure evolution can fragment the twin domains and stunt their growth.

\section{Discussion}

Many studies report similar texture evolution after one ECAE pass in a variety of hcp metals, see [2] for review, in spite of different starting textures and processing conditions. The present study on $\mathrm{Be}$ and $\mathrm{Zr}$ suggests that this similarity results from the predominance of basal and prismatic slip activity. For Be, this is not a surprising result for the easiest and second easiest slip modes in Be are basal slip and prismatic slip, respectively. For up to two to four passes, the model results suggest that the relative activities of these two mechanisms depend on pass number, route, and die angle.

The significant contribution of basal slip activity in ECAE processing of $\mathrm{Zr}$ is a surprising result. Texture evolution can only be adequately modeled with basal slip; although not shown here, suppressing basal slip leads to grossly inaccurate predictions (see [21]). In selecting the parameters for basal slip, great care was taken to ensure that it was not active in the initial stages of the extrusion in order to be consistent with previous experimental results $[23,24,26]$. This approach led to texture predictions in fair agreement with the measurement.

Basal slip was not considered in our previous work on $\operatorname{Zr}[23,24,26]$ for several reasons. Microscopic investigations of specimens after uniaxial testing showed that the dominant slip modes were prismatic slip and pyramidal $<\mathrm{c}+\mathrm{a}>$ slip [56]. Texture measurements came to the same conclusion. Experimental studies [57-59] on single crystal Zr report that basal slip is not activated unless the temperature is raised above $850 \mathrm{~K}$. While basal slip is activated above $850 \mathrm{~K}$, its critical resolved shear stress remains higher than that of prismatic. Small levels of basal slip activity have been reported in $\mathrm{Zr}$ at room temperature and lower temperatures, typically associated with cross slip from basal to prismatic planes [59,60], kink band formation [61], and regions near stress concentrators. In these cases, basal slip seems to be a local event, promoted by locally high stress levels. Without basal slip, our model was able to reproduce stress-strain curves and texture evolution during uni-axial straining in different loading directions and a wide range of temperatures, $450 \mathrm{~K}$ to $76 \mathrm{~K}$ [23]. It later proved effective in predicting stress-strain data for load path changes and temperature changes [24]. 
Most of the tests discussed above were conducted to small or moderate strain levels $(<20-25 \%)$, in uni-axial stress, and at quasi-static rates. For Zr alloys and/or other deformation states involving higher strains and pressures, however, some experimental and modeling studies have suggested that basal slip contributed significantly in deformation: cold rolling of pure $\mathrm{Zr}$ [62], ECAE of pure $\mathrm{Zr}$ [21], ECAE of Zr702 [17,20], in Zircaloy-2 in room temperature testing [63], and high strain compression of $\mathrm{Zr}-2.5 \mathrm{Nb}$ [64].

We speculate that the unexpected prevalence of basal slip in pure $\mathrm{Zr}$ could be a consequence of the large strains and/or hydrostatic pressure imposed by ECAE. It is possible that these conditions changed the mobility of basal, prismatic, and pyramidal slip dislocations in different ways. These dislocations are known to have different atomic core structures; basal dislocation cores are planar [65], prismatic screw dislocation cores are non-planar [66,67], and pyramidal dislocation cores are zonal $[65,68]$, which may have their own characteristic response to high stress, temperatures, and pressures. Also, in ECAE, dislocation substructure and grain refinement processes take place, which can generate large internal stresses. The interaction between one slip mode with substructure may be stronger than with another, such that its activation is suppressed at larger strains. Thus, it is possible that agreement with the measurement would be much improved if basal slip was allowed to play a larger role and tensile twinning a softer one. Pursuing this, however, calls for a better understanding of the behavior of basal slip dislocations during ECAE and more precise characterization of the model parameters with basal slip included.

\section{Concluding remarks}

A model is presented for the constitutive behavior of hcp metals during large strain processing. Predicting the texture, microstructural, and strength evolution during ECAE, or any large strain, high pressure SPD technique, requires a multi-length scale understanding. The current framework accounts for phenomena from the subgrain to polycrystalline scale and their connections across the scales. It is applied to pure $\mathrm{Be}$ and pure $\mathrm{Zr}$ and their texture evolution in the first few passes of ECAE. Most of the material parameters are determined by fitting the model to mechanical test data on the starting material. A significant achievement demonstrated in this work is the capability of the model to predict up to four passes solely with an initial set of parameters. No intermediate adjustments were made between passes. It should be clear that texture predictions for passes two thru four would improve even further if the experimental texture from the previous pass were used as input into the model for the next pass. This method reduces the calculations to a series of singlepass simulations and generally limits the model as a predictive SPD tool.

An important component of our multi-scale model is the dislocation density based hardening law for individual slip families in hep metals. Storage of forest and substructure dislocation populations from each slip family (basal, prismatic, pyramidal $<\mathrm{c}+\mathrm{a}>$ ) follows a separate rate law and are a function of temperature and strain rate. These populations then determine the critical resolved shear stress for the activation of each slip mode. Deformation twinning follows a different rate law and in the model, slip and twinning interactions are included. The advantage of this dislocation-based hardening model lies in its flexibility. It can treat changes in processing parameters such as temperature and strain rate. It can consider any set of slip and twinning modes particular to the hep metal. It can be used to predict the constitutive behavior of the sample after ECAE. Typically such post-mechanical tests are conducted under temperatures, strain rates, and strain paths different than those of ECAE. Accounting for slip and twinning phenomena at lowerlength scales facilitates possible model extensions for twin nucleation, dynamic recrystallization, static recovery, and grain refinement. Applications of this model to $\mathrm{Mg}$ alloys are currently underway $[9,11,12,24]$.

A few issues require further study. First, an understanding of the dislocation mobility of individual slip systems under the large strain and hydrostatic pressure conditions of ECAE is needed. Such pursuits may explain why basal slip seems to be prevalent in $\mathrm{Zr}$ during ECAE and not during traditional mechanical tests up to moderate strain levels. Second, the substructure evolution law needs to be extended to account for changes in grain size and recovery mechanisms 
associated with large strain deformation. Last, the propensity and morphology of deformation twins during ECAE of $\mathrm{Zr}$ requires further evaluation.

\section{References}

[1] V.M. Segal, V.I. Reznikov, A.E. Drobyshevski and V.I. Kopylov: Russ. Metall. Vol. 1 (1981), p. 99

[2] I.J. Beyerlein and L.S. Tóth: Prog. Mater. Sci. (2009), DOI: 10.1016/j.pmatsci.2009.01.001

[3] G.G. Yapici, I. Karaman and Z-P. Luo: Acta Mater. Vol. 54 (2006), p. 3755

[4] Y. Perlovich, M. Isaenkova, V. Fesenko, M. Grekhov, S.H. Yu, S.K. Hwang and D.H. Shin: Mater. Sci. Forum Vol. 503-504 (2005), p. 859

[5] D.H. Shin, I. Kim, J. Kim, Y.S. Kim and S.L. Semiatin: Acta Mater. Vol. 51 (2003), p. 983

[6] S.R. Agnew, P. Mehrotra, T.M. Lillo, G.M. Stoica and P.K. Liaw: Acta Mater. Vol. 53 (2005), p. 3135

[7] S.R. Agnew, J.A. Horton, T.M. Lillo and D.W. Brown: Scripta Mater. Vol. 50 (2004), p. 377

[8] S.R. Agnew, P. Mehrotra, T.M. Lillo, G.M. Stoica and P.K. Liaw: Mater. Sci. Engng. A Vol. 408 (2005), p. 72

[9] M. Al-Maharbi, D.T. Foley, I. Karaman, K.T. Hartwig, I.J. Beyerlein, S. Mathaudhu and L. Kecskes: in preparation (2009)

[10]B. Beausir, S. Suwas, L.S. Tóth, K.W. Neale and J-J. Fundenberger: Acta Mater. Vol. (2008), p. 200

[11]A. Oppedal et al.: in preparation (2009)

[12] R.B. Figueiredo, A.P. Zhilyaev, T.G. Langdon and I.J. Beyerlein (2009), in preparation.

[13]R.D. Field, K.T. Hartwig, C.T. Necker and J.F. Bingert, S.R. Agnew: Metall. Mater. Sci. Vol. 33 (2002), p. 965

[14]I.J. Beyerlein, R.D. Field, K.T. Hartwig and C.T. Necker: J. Mater. Sci. Vol. 43 (2008), p. 7465

[15] S. Li, D.J. Alexander, I.J. Beyerlein and D.W. Brown, in: Proceedings of ICOTOM-15 (2008) CD-ROM.

[16] W.S. Choi, H.S. Ryoo, S.K. Hwang, M.H. Kim, S.I. Kwun and S.W. Chae: Metall. Mater. Trans. A Vol. 33 (2002), p. 973

[17]Y. Perlovich, M. Isaenkova, V. Fesenko, M. Grekhov, I. Alexandrov and I.J. Beyerlein: Mater. Sci. Forum Vol. 503-504 (2006), p. 853

[18] W.Q. Cao, S.H. Yu, Y.B. Chun, Y.C. Yoo, C.M. Lee, D.H. Shin and S.K. Hwang: Mater. Sci. Engng. A Vol. 395 (2005), p. 77

[19] S.H. Yu, Y.B. Chun, W.Q. Cao, M.H. Kim, S.W. Chae, S.I. Kwun, D.H. Shin and S.K. Hwang: Met. Mater. Inter. Vol. 11 (2005), p. 101

[20] S.H. Yu, Y.B. Chun, S.K. Hwang and D.H. Shin: Phil. Mag. Vol. 85 (2005), p. 345

[21]G.G. Yapici, C.N. Tomé, I.J. Beyerlein, I. Karaman, S.C. Vogel, and C. Liu: submitted to Acta Mater. (2009)

[22]L.Capolungo and I.J. Beyerlein: Phys. Rev. B. Vol. 78 (2008), p. 024117

[23]I.J. Beyerlein and C.N. Tomé: Int. J. Plast. Vol. 24 (2008), p. 867

[24]L. Capolungo, I.J. Beyerlein, G.C. Kaschner and C.N. Tomé: Mater. Sci. Engng. A (2008), in press 
[25]D.W. Brown et al.: in preparation (2009)

[26] G.C. Kaschner, C.N. Tomé, I.J. Beyerlein, S.C. Vogel, D.W. Brown, and R.J. McCabe: Acta Mater. Vol. 54 (2006), p. 2887

[27]U.F. Kocks, C.N. Tomé and H.-R. Wenk: Texture and Anisotropy - Preferred Orientations in Polycrystals and their Effect on Materials Properties (Cambridge University Press 1998)

[28]R.A. Lebensohn and C.N. Tomé: Acta Metall. Mater. Vol. 41 (1993), p. 2611

[29]R.J. Asaro and A. Needleman: Acta Metall. Vol. 33 (1985), p. 923

[30]L. Capolungo, I.J. Beyerlein and C.N. Tomé: Scripta Mater. Vol. 60 (2009), p. 32

[31] Eshelby, J.D. Proc. Roy. Soc. London A Vol. 241 (1957), p. 376

[32] V.M. Segal: Mater. Sci. Engng. A Vol. 197 (1995), p. 157

[33] V.M. Segal: Mater. Sci. Engng. A Vol. 271 (1999), p. 322

Mater. Vol. 54 (2006), p. 2887

[34] V.M. Segal: Mater. Sci. Engng A Vol. 345 (2003), p. 36

[35]I.J. Beyerlein and C.N. Tomé: Mater. Sci. Engng. A Vol. 380 (2004), p. 171

[36]I.J. Beyerlein, S. Li, C.T. Necker, D.J. Alexander and C.N. Tomé: Phil. Mag. Vol. 85 (2005), p. 1359

[37]S. Li, A.A. Gazder, I.J. Beyerlein, C.H.J. Davies and E.V. Pereloma: Acta Mater. Vol. 55 (2007), p. 1017

[38] S. Li, I.J. Beyerlein, C.T. Necker: Acta Mater. Vol. 54 (2006), p. 1397

[39] S. Li, M.A.M. Bourke, I.J. Beyerlein, D.J. Alexander and B. Clausen: Mater. Sci. Engng. A Vol. 382 (2004), p. 217

[40] S. Mahesh, I.J. Beyerlein and C.N. Tomé: Scripta Mater. Vol. 53 (2005), p. 965

[41]S. Li, I.J. Beyerlein, C.T. Necker, D.J. Alexander and M.A.M. Bourke: Acta Mater. Vol. 52 (2004), p. 4859

[42]I.J. Beyerlein, R.A. Lebensohn and C.N. Tomé: Mater. Sci. Engng. A Vol. 345 (2003), p. 122

[43] S. Li, S.R. Kalidindi, I.J. Beyerlein: Mater. Sci. Engng. A Vol. 410-411 (2005), p. 207

[44]C.N. Tomé, R.A. Lebensohn and C.T. Necker: Metall. Mater. Trans. A Vol. 33 (2002), p. 2635

[45]S. Li, I.J. Beyerlein, D.J. Alexander and S.C. Vogel: Acta Mater. Vol. 53 (2005), p. 2111

[46] S.C. Vogel, I.J. Beyerlein, M.A.M. Bourke, C.N. Tomé, P. Rangaswamy, C. Xu and T.G. Langdon: Mater. Sci. Forum Vol. 408-412 (2002), p. 673

[47]J.W. Signorelli, R. Logé, P.A. Turner, V. Sordi, E.A. Vieira, M. Ferrante, R.E. Bolmaro: Mater. Sci. Forum Vol. 495-497 (2005), p. 775

[48]N.A. Enikeev, M.F. Abdullin, A.A. Nazarov and I.J. Beyerlein: Int. J. Mater. Res. Vol. 98 (2007), p. 167

[49]A.A. Nazarov, N.A. Enikeev, A.E. Romanov, T.S. Orlova, I.V. Alexandrov and I.J. Beyerlein, R.Z. Valiev: Acta Mater. Vol. 54 (2006), p. 985

[50]G. Proust, C.N. Tomé and G.C. Kaschner: Acta Mater. Vol. 55 (2007), p. 2137

[51]U. Essmann and H. Mughrabi: Phil. Mag. A Vol. 40 (1979), p. 731

[52]H. Mecking and U.F. Kocks: Acta Metall. Vol. 29 (1981), p. 1865 
[53] S.J. Basinski and Z.S. Basinski, in: Dislocations in Solids, volume 4, North-Holland, Amsterdam (1979)

[54] R. Madec, B. Devincre and L.P. Kubin: Phys. Rev. Lett. Vol. 89 (2002), p. 255508

[55]F. Aldinger, in: Beryllium Science and Technology, edited by D. Webster and G.J. London, volume 1, chapter 1, Plenum Press (1979).

[56]R.J. McCabe, E.K. Cerreta, A. Misra, G.C. Kaschner and C.N. Tomé: Phil. Mag. Vol. 86 (2006), p. 3595

[57]A. Akhtar: J. Nuclear Mater. Vol. 47 (1973), p. 79

[58]A. Akhtar: Metall. Trans. A Vol. 6 (1975), p. 1217

[59]A. Akhtar and A. Teghtsoonian: Acta Metall. Vol. 19 (197), p. 655

[60]J.I. Dickson and G.B. Craig. J Nuclear Mater. Vol. 40 (1971), p. 346.

[61]J.L. Martin and R.E. Reed-Hill: Trans. AIME. Vol. 230 (1964), p. 780

[62] M.J. Philippe and M. Serghat, P. Van Houtte, C. Esling: Acta Metall. Vol. 43 (1995), p. 1619

[63]F. Xu, R.A. Holt, M.R. Daymond: J. Nucl. Mater. Vol. 373 (2008), p. 217

[64]A. Salinas-Rodriguez: Acta Metall. Mater. Vol. 43 (1995), p. 485

[65]J.P. Hirth and J. Lothe: Theory of Dislocations (John Wiley \& Sons, Kriger Publishing Company, New York 1982)

[66]B. Legrand: Phil. Mag. A Vol. 52 (1984), p. 83

[67]D.J. Bacon and V. Vitek: Metall. Mater. Trans. A Vol. 33 (2002), p. 721

[68]H.S. Rosenbaum, in: Deformation Twinning, edited by R.E. Reed-Hill, J.P. Hirth, H.C. Rogers, volume 25 of Metallurgical Society Conferences, chapter 3, Gordon and Breach Science Publishers, New York (1964). 